\title{
PIUS Core Performance Analysis
}

Manuscript Completed: March 1996

Date Published: May 1996

Prepared by

J. F. Carew, A. Aronson, D. M. Cokinos, A. Prince, E. C. Selcow

Brookhaven National Laboratory

Upton, NY 11973-5000

D. C. Scaletti, NRC Technical Monitor

Prepared for

Division of Reactor Program Management

Office of Nuclear Reactor Regulation

U.S. Nuclear Regulatory Commission

Washington, DC 20555-0001

NRC Job Code L2034

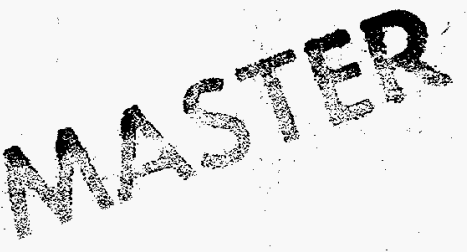




\section{DESCLATMER}

Portions of this document may be illegible in selectronic image products. Images are produced from the best available original document. 


\begin{abstract}
A detailed evaluation of the fuel-burnup dependent power distribution and the scram reactivity for the PIUS reactor design has been performed. The analyses were carried out using the CPM lattice physics and NODE-P2 core neutronics/thermal-hydraulics codes, and are based on the information provided in the PIUS Preliminary Safety Information Document.

Cycle depletion calculations were performed for a set of nine representative initial core loadings and the threedimensional core power distributions were determined. These calculations indicate that the PIUS radial $F_{\Delta h}$ and total $F_{Q}$ power peaking is stronger than that indicated by the PIUS reference-design values.

The scram reactivity resulting from the injection of highly borated pool water was calculated for a series of timedependent linear ramp and square-wave pool flows. The three-dimensional distribution of the borated pool water throughout the core was modeled and the spatial reactivity effects of the distributed boron were determined. For pool flows that increase as a linear ramp, the spatial reactivity effects of the distributed boron were very small. In this case, a constant core-average boron reactivity coefficient can be used to model the PIUS scram reactivity.
\end{abstract}

\title{
DISCLAIMER
}

This report was prepared as an account of work sponsored by an agency of the United States Government. Neither the United States Government nor any agency thereof, nor any of their employees, makes any warranty, express or implied, or assumes any legal liability or responsibility for the accuracy, completeness, or usefulness of any information, apparatus, product, or process disclosed, or represents that its use would not infringe privately owned rights. Reference herein to any specific commercial product, process, or service by trade name, trademark, manufacturer, or otherwise does not necessarily constitute or imply its endorsement, recommendation, or favoring by the United States Government or any agency thereof. The views and opinions of authors expressed herein do not necessarily state or reflect those of the United States Government or any agency thereof. 


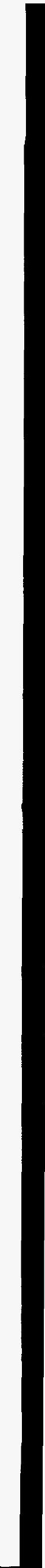




\section{Contents}

Page

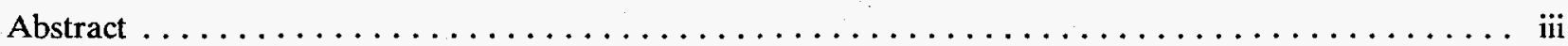

List of Figures $\ldots \ldots \ldots \ldots \ldots \ldots \ldots \ldots \ldots \ldots \ldots \ldots \ldots \ldots \ldots \ldots \ldots \ldots \ldots \ldots \ldots \ldots$

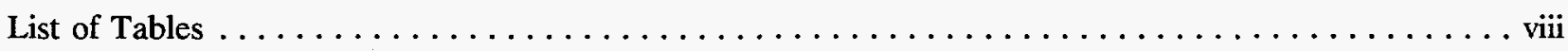

Acknowledgements $\ldots \ldots \ldots \ldots \ldots \ldots \ldots \ldots \ldots \ldots \ldots \ldots \ldots \ldots \ldots \ldots \ldots \ldots \ldots \ldots \ldots \ldots$

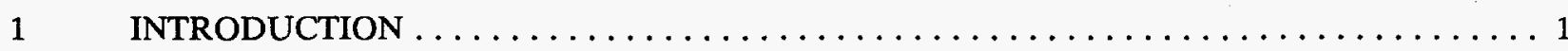

2 CALCULATIONAL METHODOLOGY $\ldots \ldots \ldots \ldots \ldots \ldots \ldots \ldots \ldots \ldots$

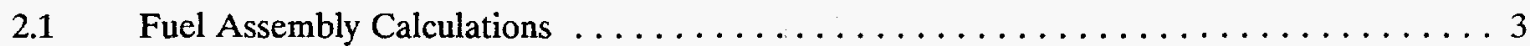

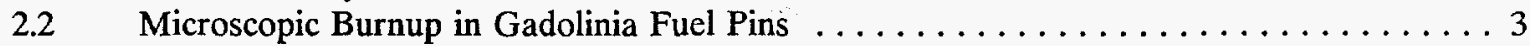

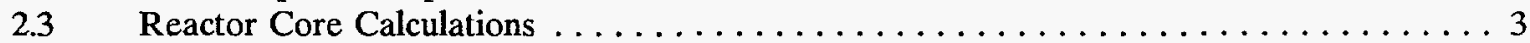

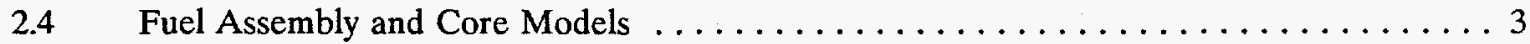

3 POWER DISTRIBUTION ANALYSIS $\ldots \ldots \ldots \ldots \ldots \ldots \ldots \ldots \ldots \ldots \ldots \ldots \ldots \ldots$

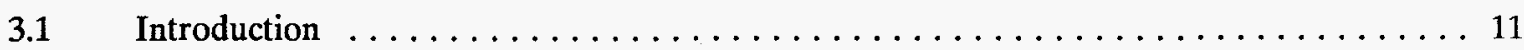

3.2 Fuel-burnup Dependent Power Peaking $\ldots \ldots \ldots \ldots \ldots \ldots \ldots \ldots \ldots \ldots \ldots \ldots \ldots \ldots$

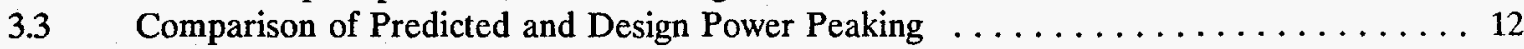

$3.4 \quad$ Moderator and Fuel Temperature Coefficient Calculations $\ldots \ldots \ldots \ldots \ldots \ldots \ldots 12$

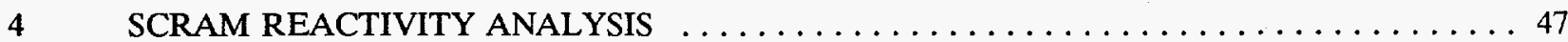

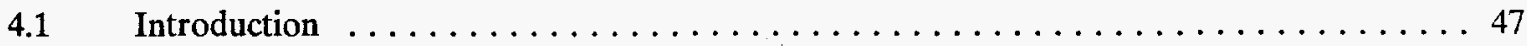

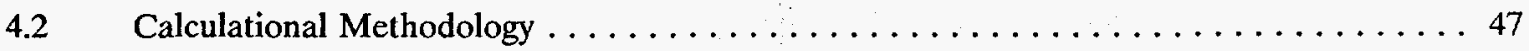

4.2.1 Reactivity Analysis . . . . . . . . . . . . . . . . . 47

4.2.2 Determination of the Core Boron Distribution $\ldots \ldots \ldots \ldots \ldots \ldots \ldots \ldots . \ldots 7$

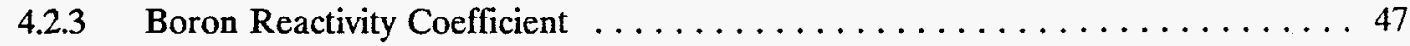

4.3 Analysis Results and Discussion $\ldots \ldots \ldots \ldots \ldots \ldots \ldots \ldots \ldots \ldots \ldots \ldots$

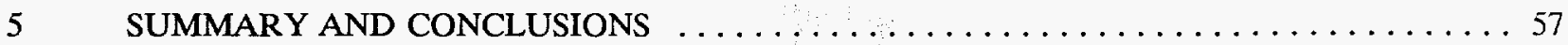

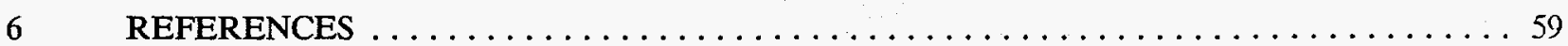




\section{List of Figures}

Figure

Page

2.1 Typical Gd Loading Pattern, $18 \times 18$ Fuel Assembly $\ldots \ldots \ldots \ldots \ldots \ldots \ldots \ldots \ldots$

2.2 Axial $\mathrm{Gd}_{2} \mathrm{O}_{3}$ Variation of Initial Fuel $\ldots \ldots \ldots \ldots \ldots \ldots \ldots \ldots \ldots \ldots \ldots \ldots \ldots$

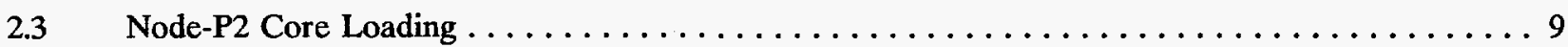

3.1 PIUS Gd Assembly Distribution, Radial Configuration, Case A $\ldots \ldots \ldots \ldots \ldots \ldots \ldots$

3.2 PIUS Gd Assembly Distribution, Radial Configuration, Case B $\ldots \ldots \ldots \ldots \ldots \ldots \ldots$

3.3 PIUS Gd Assembly Distribution, Radial Configuration, Case $\mathrm{C} \ldots \ldots \ldots \ldots \ldots \ldots \ldots$

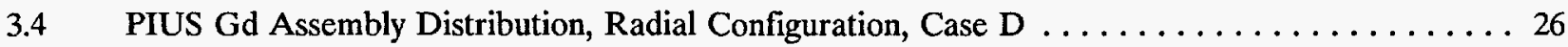

3.5 PIUS Gd Assembly Distribution, Radial Configuration, Case E $\ldots \ldots \ldots \ldots \ldots \ldots \ldots$

3.6 PIUS Gd Assembly Distribution, Radial Configuration, Case $\mathrm{F} \ldots \ldots \ldots \ldots \ldots \ldots \ldots$

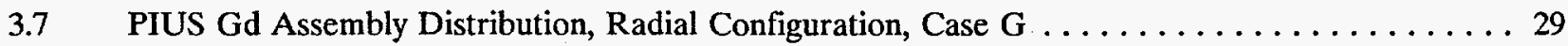

3.8 PIUS Gd Assembly Distribution, Radial Configuration, Case $\mathbf{H} \ldots \ldots \ldots \ldots \ldots \ldots \ldots$

3.9 PIUS Gd Assembly Distribution, Radial Configuration, Case I $\ldots \ldots \ldots \ldots \ldots \ldots \ldots \ldots$

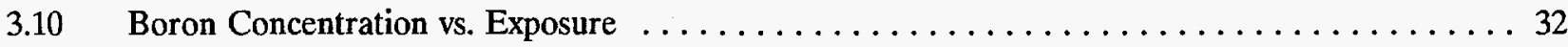

3.11 Assembly Relative Power at $0 \mathrm{MWD} / \mathrm{T}$ Exposure $\ldots \ldots \ldots \ldots \ldots \ldots \ldots \ldots \ldots \ldots$

3.12 Assembly Relative Power at $500 \mathrm{MWD} / \mathrm{T}$ Exposure $\ldots \ldots \ldots \ldots \ldots \ldots \ldots \ldots \ldots \ldots$

3.13 Assembly Relative Power at 2000 MWD/T Exposure $\ldots \ldots \ldots \ldots \ldots \ldots \ldots \ldots \ldots \ldots$

3.14 Assembly Relative Power at $4000 \mathrm{MWD} / \mathrm{T}$ Exposure $\ldots \ldots \ldots \ldots \ldots \ldots \ldots \ldots \ldots$

3.15 Assembly Relative Power at 6000 MWD/T Exposure $\ldots \ldots \ldots \ldots \ldots \ldots \ldots \ldots \ldots \ldots$

3.16 Assembly Relative Power at 8000 MWD/T Exposure $\ldots \ldots \ldots \ldots \ldots \ldots \ldots \ldots \ldots$

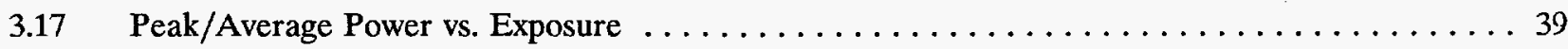

$3.18 \quad$ Average Axial Power vs. Core Height $\ldots \ldots \ldots \ldots \ldots \ldots \ldots \ldots \ldots \ldots \ldots \ldots \ldots \ldots \ldots \ldots \ldots$

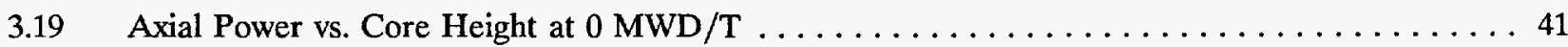

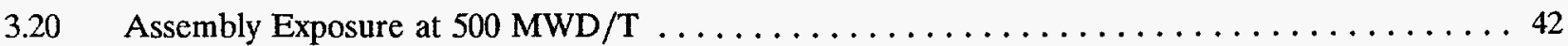




\section{List of Figures (Cont'd.)}

Figure Page

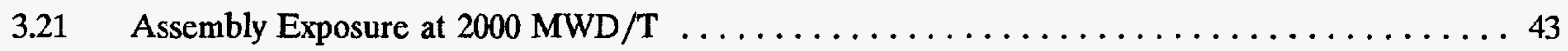

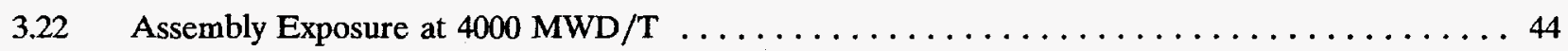

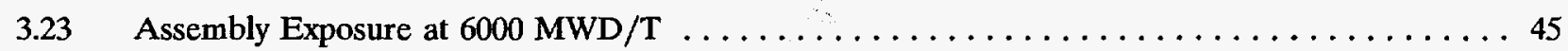

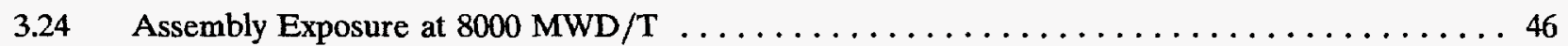

4.1 Scram Reactivity as a Function of Core Average Boron Concentration $\ldots \ldots \ldots \ldots \ldots \ldots$

4.2 Dependence of the Scram Reactivity on the Ramp Pool Flow Rate $-\alpha \ldots \ldots \ldots \ldots \ldots$

4.3 Dependence of the Scram Reactivity on the Pool Water Temperature $\ldots \ldots \ldots \ldots \ldots \ldots$

4.4 Dependence of the Scram Reactivity on Fuel Burnup $\ldots \ldots \ldots \ldots \ldots \ldots \ldots \ldots \ldots$

4.5 Scram Reactivity for a Strong $(\beta=0.15)$ Square-Wave Pulse of Pool Flow $\ldots \ldots \ldots \ldots 5$

4.6 Scram Reactivity vs. Spatially-Weighted Core Average Boron Concentration . . . . . . . 56 


\section{List of Tables}

Tables

$2.1 \quad$ Fuel Assembly Data $\ldots \ldots \ldots \ldots \ldots \ldots \ldots \ldots \ldots \ldots \ldots \ldots \ldots \ldots \ldots \ldots \ldots \ldots$

2.2 Preliminary Reactor Core Description $\ldots \ldots \ldots \ldots \ldots \ldots \ldots \ldots \ldots \ldots \ldots \ldots$

3.1 Power Distribution Peaking for the Selected Initial Core Loadings $\ldots \ldots \ldots \ldots \ldots \ldots$

3.2 Case A Core Performance Parameter Summary $\ldots \ldots \ldots \ldots \ldots \ldots \ldots \ldots \ldots \ldots \ldots$

3.3 Case B Core Performance Parameter Summary $\ldots \ldots \ldots \ldots \ldots \ldots \ldots \ldots \ldots \ldots$

3.4 Case $\mathrm{C}$ Core Performance Parameter Summary $\ldots \ldots \ldots \ldots \ldots \ldots \ldots \ldots \ldots \ldots$

3.5 Case D Core Performance Parameter Summary $\ldots \ldots \ldots \ldots \ldots \ldots \ldots \ldots \ldots \ldots$

3.6 Case E Core Performance Parameter Summary $\ldots \ldots \ldots \ldots \ldots \ldots \ldots \ldots \ldots \ldots \ldots$

3.7 Case F Core Performance Parameter Summary $\ldots \ldots \ldots \ldots \ldots \ldots \ldots \ldots \ldots \ldots \ldots$

3.8 Case G Core Performance Parameter Summary $\ldots \ldots \ldots \ldots \ldots \ldots \ldots \ldots \ldots \ldots \ldots$

3.9 Case $\mathrm{H}$ Core Performance Parameter Summary $\ldots \ldots \ldots \ldots \ldots \ldots \ldots \ldots \ldots \ldots$

Case I Core Performance Parameter Summary $\ldots \ldots \ldots \ldots \ldots \ldots \ldots \ldots \ldots \ldots \ldots \ldots$

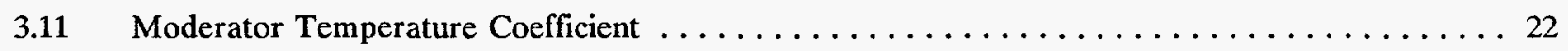

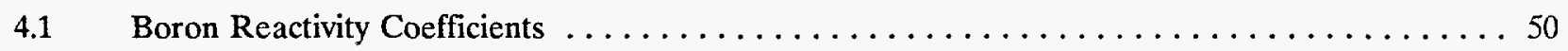




\section{Acknowledgements}

The work documented in this report was performed under the auspices of the United States Nuclear Regulatory Commission (USNRC). It was funded by the Advanced Reactors Project Directorate and Associate Director for Advanced Reactors and License Renewal, in the office of Nuclear Reactor Regulation, under FIN Number L-2034. The program was monitored at the USNRC by Dino Scaletti and Joseph Donoghue, whose support of this work is greatly appreciated.

Special thanks is also due Mrs. N. Siemon who accomplished the difficult task of editing and bringing this final report into compliance with NRC documentation requirements. 


\section{Introduction}

The ABB Atom PIUS (Process Inherent Ultimately Safe) reactor is designed to include passive safety features to provide protection against severe accidents and core degradation. These safety features are inherent in the plant configuration and do not take credit for the functioning of active components or correct operator action during reactor transients and emergencies. The elimination of active components has an important effect on the PIUS operation and core performance. The PIUS reactor control and scram system does not include the typical electro-mechanical control and shutdown rods used in LWR designs, but relies on the injection of highly borated water from a surrounding pool during a reactor upset. This fundamental difference between the PIUS and present LWR designs has resulted in some concern with respect to the PIUS core performance and shutdown reactivity systems. Without movable control rods the PIUS design provides only limited control of the power distribution, which is expected to undergo significant changes during the fuel-burnup cycle and during core xenon oscillations. The power distribution fuel-burnup dependence is expected to be particularly strong in PIUS due to the extensive use of burnable poisons. Increased power peaking will result in a proportionate decrease in the margin to the fuel melt, LOCA and DNBR limits. In addition, the strength and timing characteristics of the PIUS scram reactivity resulting from the time-dependent injection of soluble boron require detailed evaluation.

In response to these concerns and as part of the NRC preapplication design review and preparation for future Part-52 design certification of the PIUS design, the Advanced Reactors Project Directorate and Associate Director for Advanced Reactors and License Renewal established the "PIUS Reactor Design Core Analysis" Program (FIN-L-2034) at Brookhaven National Laboratory. The purpose of this program is to develop methods and models for performing core performance analyses, and to carry out specific evaluations to confirm acceptable safety margins of the PIUS reactor design. This report documents the initial analyses performed under this program and includes: (1) the construction of a detailed coupled neutronics/thermal-hydraulics model of the PIUS core, (2) evaluation of the PIUS cycledependent power distribution peaking, (3) evaluation of the PIUS feedback coefficients and (4) analysis of the PIUS scram reactivity characteristics.
The present analyses are based on the design data presented in the "PIUS Preliminary Safety Information Document" (PSID) given in Reference-1 and the response to the request for additional information on the PIUS design provided by ABB atom in Reference- 2 . Since the PIUS design as described in the PSID has not been finalized, this analysis is considered to be a preliminary or scoping analysis in which potential safety issues are identified. It is intended that detailed design evaluations of the issues identified in this analysis will be performed when the design is finalized.

In this analysis, the three-dimensional coupled neutronics/thermal-hydraulics calculations were performed with NODE-P2 (Reference-3). The CPM fuel assembly code (Reference-4) was used to determine detailed few group lattice physics data as a function of fuel burnup, moderator density, fuel temperature and boron concentration. This fuel assembly data was input to the three-dimensional core model which was used to calculate the cycle-dependent core-wide power and exposure distributions, boron scram reactivity worth and the feedback reactivity coefficients for an initial cycle of PIUS. Both NODE-P2 and the SUPERLINK-P CPM/NODE-P2 interface code were modified to accommodate the PIUS low enriched fuel and the high weight percent of gadolinium. Additional NODE-P2 modifications were also required to track the spatially dependent boron distribution through the core during the scram.

The core performance evaluation includes the calculation of the three-dimensional power peaking as a function of cycle-burnup for a relatively complete set of core loading patterns. The total $F_{Q}$ and hot-channel fucl enthalpy peaking factor $F_{\Delta h}$ are calculated and, for the cases analyzed, the calculated power peaking was found to be greater than the PIUS PSID limits. The inserted scram reactivity due to the boron pool injection was calculated for a series of time-dependent pool flows. The calculated scram reactivity was found to be a linear function of the core average boron concentration for the case of slowly increasing pool flow rates.

The methods and models used in this analysis are presented in Section-2. The application of the methodology to the power peaking and scram reactivity is given in Sections 3 and 4, respectively, and the results of the analysis are summarized in Section-5. 



\section{Calculational Methodology}

The fuel assembly nuclear data, pin-wise power distributions and few group constants were determined using the CPM collision probability module. The few group data was determined as a function of exposure, moderator density, boron concentration and fuel temperature. This assembly data was input to the NODE-P2 three-dimensional nodal model, which was used to calculate the core-wide power and exposure distributions and core reactivity for PIUS at rated and near-rated conditions. Each of these steps is described in the following sections.

\subsection{Fuel Assembly Calculations}

The fuel assemblies were calculated using the CPM multigroup two-dimensional collision probability model. The assembly geometry consisted of a square array of cylindrical fuel rods of varying compositions. The gadolinia loaded fuel rods, thimble tubes, and interassembly water gaps were treated explicitly. The basic CPM microscopic cross-section library included 69 groups.

A special module was used for the treatment of the effective cross-sections in the resonance region for important resonance absorbers, and an equivalence expression related the heterogeneous problem to an equivalent homogeneous problem. Effective absorption and fission cross-sections were calculated from the resonance integrals which were obtained from the equivalence expression. Corrections were applied for overlap effects in mixtures of resonance absorbers and for the screening effects between different pins (Dancoff effect).

\subsection{Microscopic Burnup in Gadolinia Fuel Pins}

A one-dimensional neutron transport analysis of the fuel rod and the depletion of gadolinia in annular rings was performed with MICBURN. The 69-group transport calculation was carried out in cylindrical geometry using four material regions - fuel with burnable absorber surrounded by clad, moderator and buffer zones. The initial regions were divided into a number of macroregions for which collision probabilities were calculated using the flat source approximation.

MICBURN used the same cross-section library group structure as was used for CPM. The gadolinia fueled region was modeled in MICBURN with ten radial rings to provide sufficient detail to calculate the radial flux distribution. These radial rings were expanded to thirty radial regions for the actual gadolinia depletion. The cladding region was modeled with one radial ring and the moderator and buffer regions were each modeled with two rings. The buffer region composition was made up of the fuel rod and moderator compositions adjacent to the gadolinia fuel rod. The enrichment of the fuel in the buffer region was consistent with the fuel rod enrichment. The burnup calculation included the gadolinia chain, the burnup of heavy nuclides and the build-up of fission products. The buffer zone was also depleted.

The cross sections in the data library are tabulated for different temperatures. Linear interpolation was used for intermediate temperature values within the tabulated range. The library included fission spectra for both U-235 and Pu-239, and in a depleted assembly an appropriate average fission spectrum was employed.

\subsection{Reactor Core Calculations}

NODE-P2 was used to determine the core effective multiplication, and the three-dimensional power, xenon and fuel exposure distributions. Partial and full length gadolinia-loaded fuel rods were modeled. Each fuel assembly used in the quarter-core calculation was explicitly represented and divided into axial segments or nodes. A quarter-core geometry with four distinct fuel types and 16 axial nodes was employed.

NODE-P2 employs a modified one-group diffusion theory model in which the infinite multiplication factor, $\mathrm{k}_{\infty}$, and migration area, $\mathbf{M}^{2}$, are used to determine the local reactivities. The appropriate coupling between the power distribution and nuclear properties, which are functions of coolant flow, fuel temperature, xenon and burnup, was determined iteratively. The operating conditions including thermal power, core pressure, inlet subcooling and core flow were provided as input to the cycle depletion calculation.

\subsection{Fuel Assembly and Core Models}

The PIUS design data used in constructing the CPM fuel assembly and NODE-P2 core models was obtained from the PSID and Reference-2 ABB-CE documentation. CPM employs detailed fuel assembly data including fuel rod diameters, pitch and loadings, and thermal-hydraulic operating conditions. The NODE-P2 core design data 
including assembly pitch, core power level, flow, inlet subcooling, cycle length, boron concentration and fuel temperatures were taken from these references. Essentially all the design data required for these calculations was available, except for the detailed distribution and loading of the $\mathrm{Gd}_{2} \mathrm{O}_{3}$ burnable poison. In this case, the pin-wise gadolinium loadings were based on preliminary information provided by ABB-CE (Reference-2) and the core locations of the 36 gadolinium loaded fuel assemblies were determined by a preliminary BNL core design study and were varied as part of the power peaking evaluation (Section-3).

The PIUS core consists of 213 fuel assemblies, each containing 316 fuel rods and eight guide thimbles (four located on the assembly corners) arranged in an $18 \times 18$ rod array. The corner and inner guide thimbles consist of thick-walled zircaloy tubes. The gadolinia loaded fuel assembly is assumed to contain $\mathbf{3 2}$ gadolinia fuel rods and have the PIUS intermediate $2.31 \mathrm{w} / \mathrm{o}$ U-235 enrichment. The fuel assembly configuration is shown in Figure 2.1. As shown in Figure 2.2, the gadolinia loaded $\left(\mathrm{Gd}_{2} \mathrm{O}_{3}\right)$ rods are axially graded and define three fuel types based on the amount of gadolinia present. The Type- 2 fuel is located at the top and bottom of the gadolinium loaded assembly and has no gadolinium. In the Type-3 transition-zone fuel, every other pellet is loaded with gadolinia and this fuel is taken to have an effective rodaverage gadolinium concentration of $2.0 \mathrm{w} / \mathrm{o}$. Every pellet in the Type- 4 central-zone fuel contains gadolinium and the rod-average gadolinium concentration is taken to be $4.0 \mathrm{w} / \mathrm{o}$. The exact axially dependent gadolinium concentration for the PIUS fuel was not available at the time of these calculations, and the values selected are based on preliminary information provided by ABB Atom. The axial distribution of the $2.0 \mathrm{w} / \mathrm{o}$ and $4.0 \mathrm{w} / \mathrm{o}$ gadolinium concentrations is shown in Figure 2.2.

The fuel assemblies without gadolinium have an enrichment of $1.35 \mathrm{w} / \mathrm{o}$ or $2.31 \mathrm{w} / \mathrm{o}$ U-235 and are arranged in the checkerboard pattern of Figure 2.3. The combination of $\mathrm{UO}_{2}$ enrichment and Integral Burnable Absorber (IBA) results in four distinct fuel types which are summarized in Table 2.1.

A summary of the PIUS core design characteristics used in this analysis is given in Table 2.2. The reactor core map and the location of the fuel assemblies by region is provided in Figure 2.3. The locations of the 36 fuel assemblies containing burnable poison rods for the base or reference calculation are indicated as fuel Type-C in Figure 2.3.

Table 2.1 Fuel Assembly Data

\begin{tabular}{|c|c|c|c|c|}
\hline \hline Fuel Type & $\mathbf{1}$ & $\mathbf{2}$ & $\mathbf{3}$ & $\mathbf{4}$ \\
\hline Enrichment (w/o U235) & 1.35 & 2.31 & 2.31 & 2.31 \\
Enrichment (w/o Gd $\left.\mathrm{O}_{3}\right)$ & 0.0 & 0.0 & 2.0 & 4.0 \\
\hline \hline
\end{tabular}




\section{General Characteristics}

Core rated power, MWt

Number of Assemblies

213

Core equivalent diameter (in)

148.03

Core average active fuel height (in)

98.426

Power density (W/Gm-U)

24.8

Average fuel temperature $\left({ }^{\circ} \mathrm{F}\right)$

878

Maximum fuel temperature $\left({ }^{\circ} \mathrm{F}\right)$

1292

Moderator temperature $\left({ }^{\circ} \mathrm{F}\right)$

527

Soluble boron concentration (ppm)

400

Average core pressure (psia)

1305

\section{Fuel Assembly Data}

Rod array

$18 \times 18$

Fuel rods per assembly

316

Rod pitch (in)\#

0.496

Assembly pitch (in)*

Assembly length (in)

$8.9685 \times 8.9685$

Active fuel length (in)

111.024

Number of spacer grids

98.425

Composition of spacer grid

4

Support tubes, in corners

Support tubes, inside assembly

Zircaloy-4

4

4 (instrument holes)

Fuel Weight $\left(\mathrm{UO}_{2}\right)$, (lb)

Uranium Weight (lb)

$177,502.5$

\#All dimensions are given at cold $\left(68^{\circ} \mathrm{F}\right)$ conditions.

* Center-to-center assembly pitch. 
Calculational Methodology

Table 2.2 Preliminary Reactor Core Description (Cont'd.)

3. Fuel Rod Data

Clad O.D. (in)

0.374

Clad thickness (in)

0.0225

Diametral gap (in)

0.0065

Clad material

Zircaloy-4

4. Fuel Pellet Data

\section{Material}

Density (\% of theoretical)

$\mathrm{UO}_{2}$

Enrichment (w/o)

Region 1

Region 2

Diameter (in)

95

1.35

2.31

0.3228

\section{Burnable Poison Rod Data}

Material

6. Guide Thimbles and Instrument

\section{Thimble Data}

Number of guide thimbles

Number of instrument thimbles

Composition of thimbles

Guide Thimble O.D. (in) upper

Guide Thimble I.D. (in) upper

Guide Thimble O.D. (in) lower

Guide Thimble I.D. (in) lower

Instrument Thimble O.D. (in)

Instrument Thimble I.D. (in)
Gadolinia $\left(\mathrm{Gd}_{2} \mathrm{O}_{3}\right)$

Dimensions same as fuel 


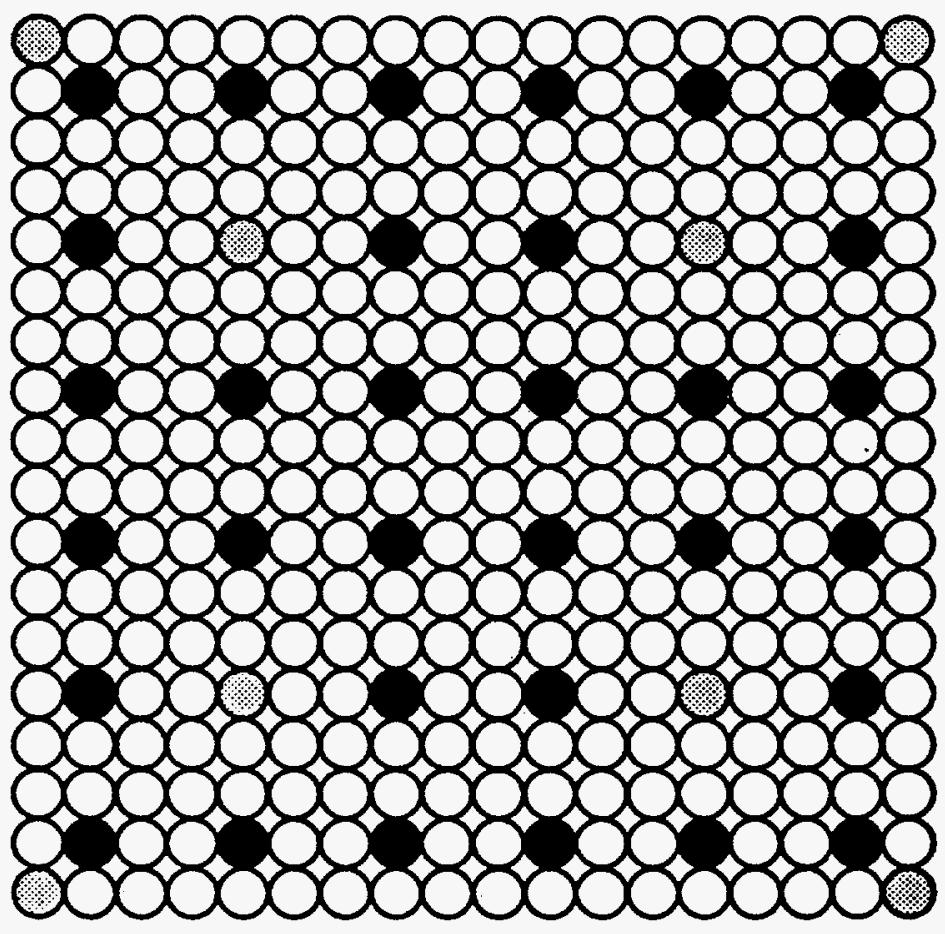

$\bigcirc$ Fuel rod, 2.31 wt \% Enrichment

- Guide thimble

- $\mathrm{Gd}_{2} \mathrm{O}_{3}$ rod, 4.0 wt \%

\section{$18 \times 18$ Fuel Assembly Typical Gd Loading Pattern}

Figure 2.1 


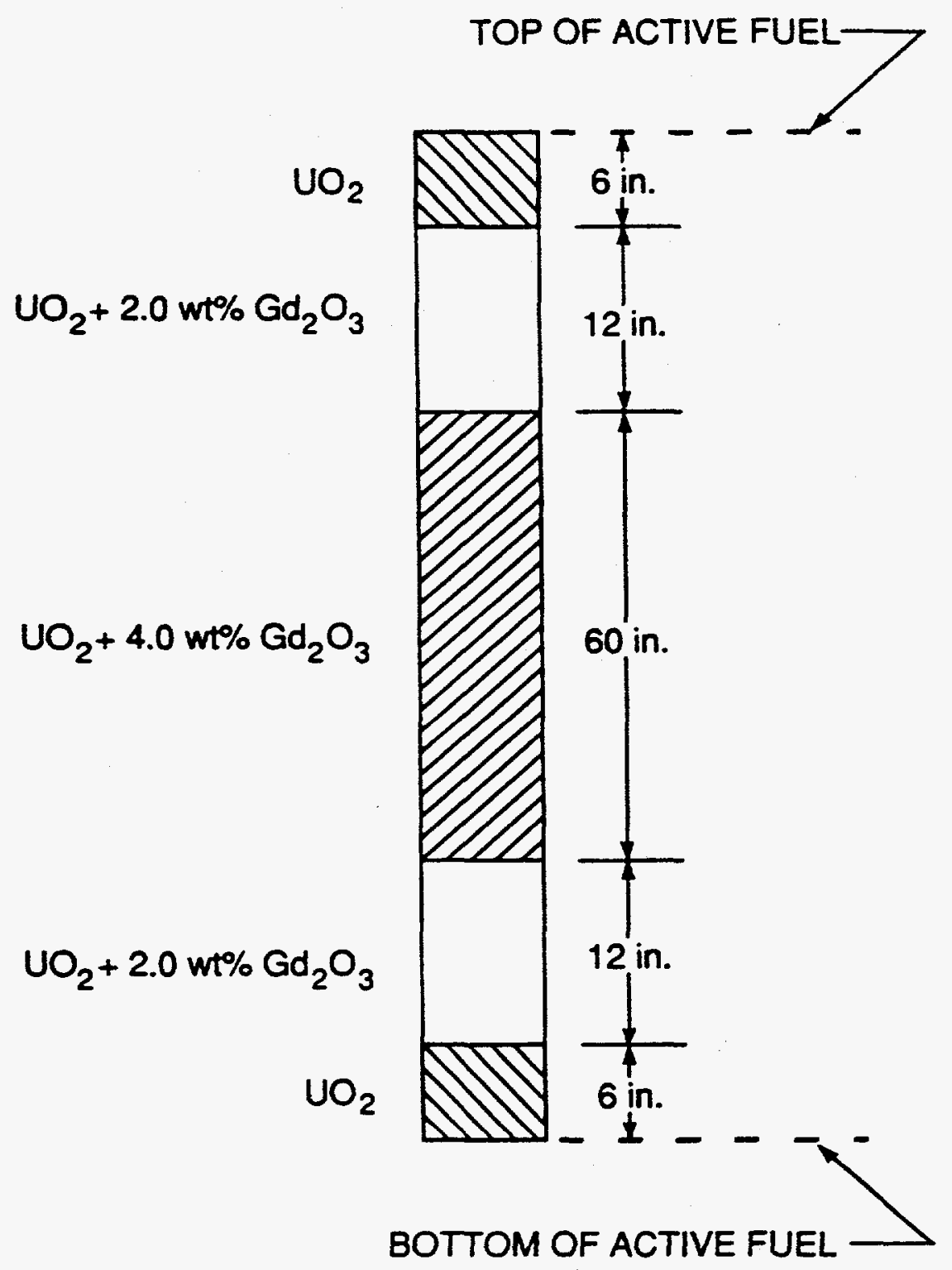

Axial $\mathrm{Gd}_{2} \mathrm{O}_{3}$ Variation of Initial Fuel

Figure 2.2 
Calculational Methodology

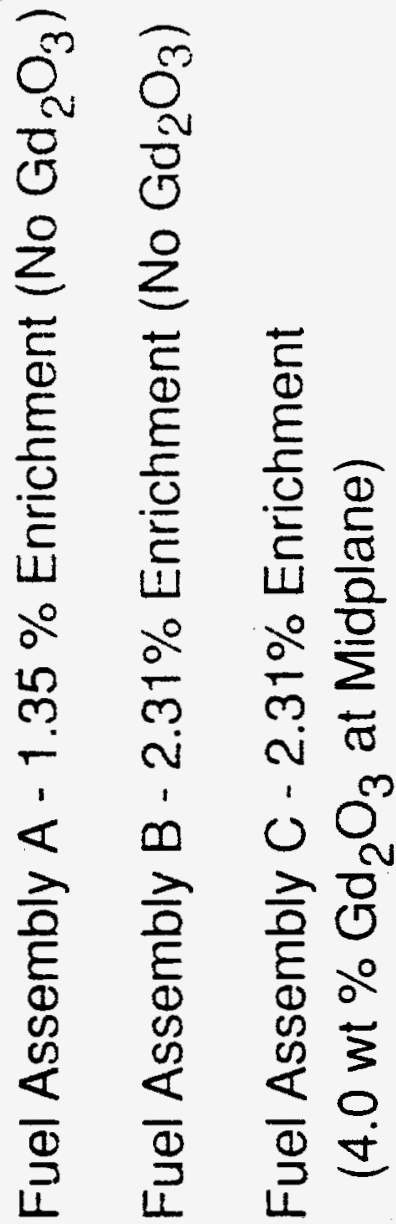

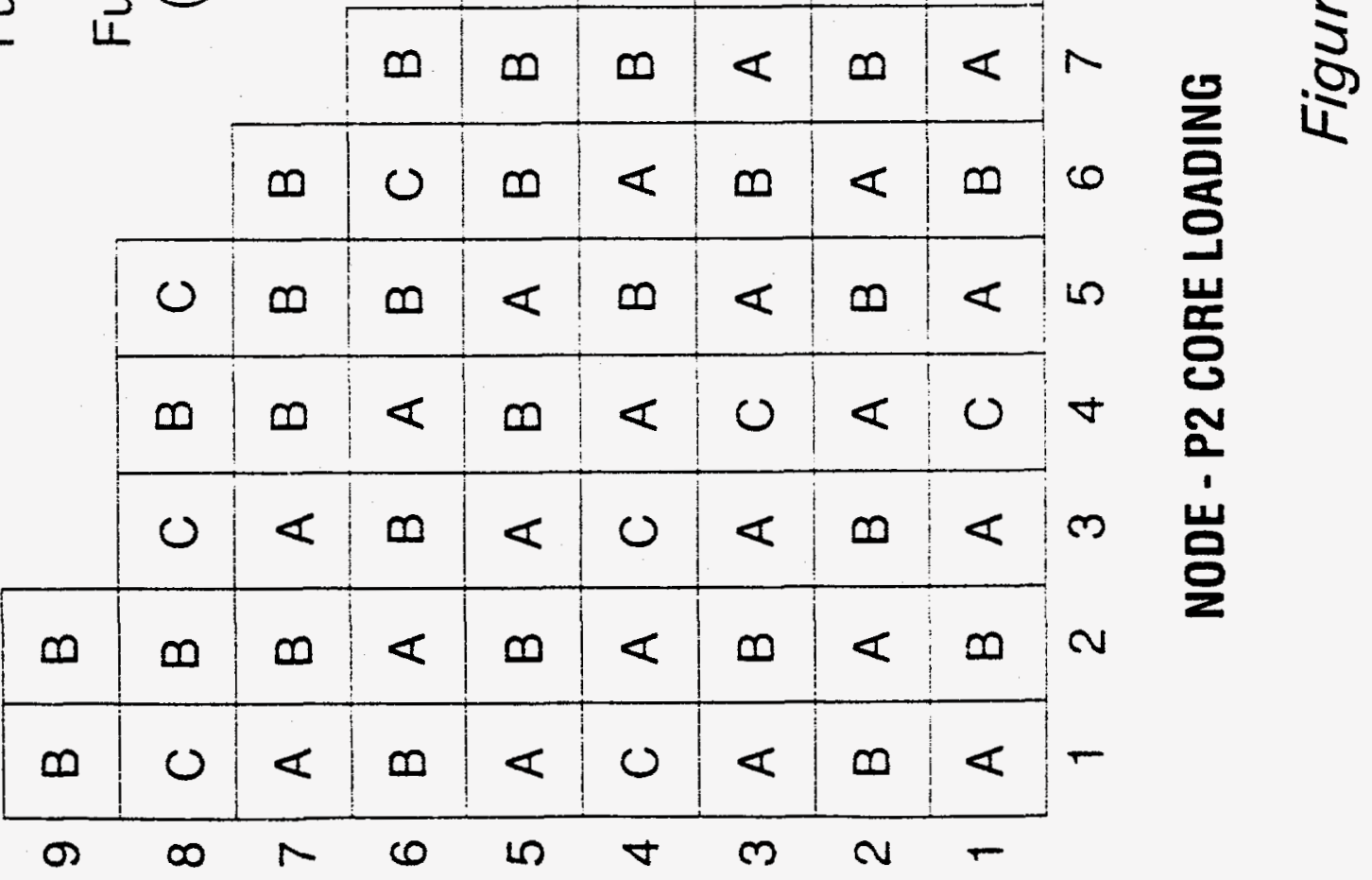




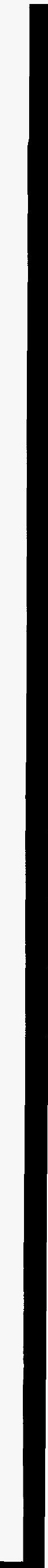




\section{Power Distribution Analysis}

\subsection{Introduction}

The General Design Criteria requires that adequate margin be provided to protect from the fuel melt and DNB limits. In the PIUS design the assurance of this margin is made difficult by two factors. First, the PIUS design does not include control rods to offset spatial reactivity effects and provide control of the core power distribution. In addition, the relatively large weight percent of gadolinium introduced to compensate for the reduced soluble boron poison results in large changes in the power distribution during the fuel-burnup cycle.

The power distribution and margin to fuel limits is determined by the fuel assembly design and the initial core loading pattern. The PIUS design includes 36 gadolinium loaded fuel assemblies and by an optimum placement of these assemblies the power peaking may be minimized. In order to determine the minimum power peaking that can be achieved by adjusting the core loading pattern, PIUS cycle burnup analyses were performed for a typical set of gadolinium fuel loading patterns.

\subsection{Fuel-burnup Dependent Power Peaking}

In the base or reference core loading pattern of Figure 2.3 , the 36 gadolinium loaded fuel assemblies are arranged in a relatively uniform pattern with maximum separation between gadolinium assemblies to minimize the power peaking during the fuel-burnup cycle. In order to estimate the minimum peaking that may be achieved with this fuel design, a series of cycle depletion calculations were performed for the nine fuel loading patterns given in Figures 3.1 -3.9. Case-A of Figure 3.1 is the reference or base loading pattern given in Figure 2.3. These loading patterns are considered to provide an approximate lower bound on the power peaking.

NODE-P2 cycle depletion calculations were performed for each of the Figure 3.1 - 3.9 fuel loading patterns. A detailed set of edits for the reference Case-A of Figure 3.1 is provided in Figures 3.10-3.24 as a function of fuel burnup. The critical boron concentration is given in Figure -3.10 , the assembly-wise radial power distributions at selected burnups are given in Figures 3.11 - 3.16, and the fuel assembly and nodal power peaking factors are given in Figure 3.17. It is important to note that these power peaking factors do not include the assembly pin peaking factor (i.e., assembly peak pin to average pin) which will be included later. The core-average axial power distribution versus burnup is given in Figure 3.18 and the beginning-of-cycle (BOC) axial distribution for several fuel assemblies is given in Figure 3.19. The assembly-wise fuel-burnup distributions throughout the cycle are given in Figures 3.20-3.24.

The calculated core power peaking for the selected fuel loading patterns is presented in Table 3.1. The coreaverage axial power distribution peaking is given in Column 3 and is seen to remain essentially constant as the radial loading pattern is changed. The axial peaking is maximum and bottom-peaked at BOC and decreases with fuel burnup as seen in Figure 3.18.

The radial power peaking factor $F_{\Delta h}$, including a rod-toassembly peaking factor of 1.2 , is given in Column 4 of Table 3.1 and is seen to be strongly dependent on the initial fuel loading. The radial power peaking is minimum when the gadolinium fuel assemblies are distributed uniformly over the core (compare Cases B and C). The maximum radial peaking generally occurs at BOC, when the gadolinium loaded fuel assembly power is low, and tends to decrease with fuel burnup. However, Cases B and I minimize the central peak at BOC, with the placement of the poisoned assemblies near the core center, and the maximum radial peaking occurs at end-ofcycle (EOC) close to the core boundary. The critical boron and power peaking versus fuel burnup are given for each fuel loading pattern in Tables 3.2 - 3.10.

The overall three-dimensional peaking factor $F_{Q}$ is given in Column 6 of Table 3.1. This peaking factor includes a local rod-to-assembly peaking factor of 1.2. Since the axial $\left(F_{\mathrm{Z}} \sim 1.39\right)$ and local $\left(\mathrm{F}_{\mathrm{L}}=1.2\right)$ peaking factors are essentially independent of the core loading, the Case-B fuel loading pattern yields both the minimum $F_{\Delta h}=1.78$ radial and $F_{O}=2.40$ total peaking factors. While every possible core loading pattern was not considered, the set of 9 patterns included in Table 3.1 is considered to be relatively complete and the minimum peaking factors determined for Case- $\mathrm{B}$ are considered to be reasonable estimates of the power peaking for the fuel design considered. 


\subsection{Comparison of Predicted and Design Power Peaking}

The PIUS design power peaking factors given in the PSID are (1) an axial peaking factor of $F_{z}=1.4,(2)$ a radial peaking factor of $F_{\Delta h}=1.55$ and (3) an overall total peaking factor of $F_{Q}=2.17$. These design peaking factors are assumed to include an allowance for uncertainty. The Case-B minimum peaking factors determined in this study are substantially larger than the values given in the PSID; the PIUS design $F_{\Delta h}=1.55$ compares with the Case- $B$ value of $F_{\Delta h}=1.78$ and the PIUS design $F_{Q}=2.17$ compares with the Case-B value of $F_{Q}=2.40$. When uncertainties are included in the Case-B peaking factors these differences will increase further.

The PIUS design has not been finalized and the present analysis was carried out as a preliminary or scoping evaluation. These calculations suggest, however, that without control rods to offset the changes in local reactivity and the resulting changes in the power distribution that occur during the fuel cycle, there may not be sufficient margin in the PIUS PSID design power peaking factors to protect the local fuel and DNBR limits.

\subsection{Moderator and Fuel Temperature Coefficient Calculations}

The moderator temperature coefficient was calculated for the minimum peaking Case-B fuel loading pattern. The moderator temperature was varied by increasing the inlet subcooling, and the moderator temperature coefficients were determined based on the core volume-averaged moderator temperature. The moderator temperature coefficient was determined at rated conditions as a function of fuel burnup. The temperature coefficients are given in Table 3.11 and indicate an initial value of -19.4 $\mathrm{pcm} /{ }^{\circ} \mathrm{C}$ and a coefficient of $-29.3 \mathrm{pcm} /{ }^{\circ} \mathrm{C}$ at EOC. The corresponding PIUS design values are $-36 \mathrm{pcm} /{ }^{\circ} \mathrm{C}$ and $46 \mathrm{pcm} /{ }^{\circ} \mathrm{C}$ at $\mathrm{BOC}$ and $\mathrm{EOC}$, respectively. The 10 $\mathrm{pcm} /{ }^{\circ} \mathrm{C}$ increase in the coefficient during the cycle due to the decrease in soluble boron and gadolinium depletion is indicated in both the calculated and design values. The initial lower calculated value is due, in part, to the specific Case-B fuel loading. In order to estimate the effect of the moderator temperature history on the temperature coefficient, an additional cycle depletion was performed for a case in which the core average temperature was increased by $11^{\circ} \mathrm{C}$. These calculations indicated that the moderator history dependence of the moderator temperature coefficient was very small and $\approx 5 \%$.

The fuel temperature doppler coefficient was calculated for the reference core design (Case-A) at hot-full-power BOC conditions at an average fuel temperature of $516.4^{\circ} \mathrm{C}$. The doppler coefficient was calculated to be $\alpha_{\mathrm{D}}$ $=-3.3 \times 10^{-5}\left[\Delta \mathrm{k} / \mathrm{k} /{ }^{\circ} \mathrm{C}\right]^{*}$ which compares with the PSID value of $\alpha_{\mathrm{D}}=-3.1 \times 10^{-5}\left[\Delta \mathrm{k} / \mathrm{k} /{ }^{\circ} \mathrm{C}\right]$.

*The actual calculated value has been decreased by $25 \%$ to account for a known bias in the CPM doppler calculation (Reference-5). 
Table 3.1 Power Distribution Peaking for the Selected Initial Core Loadings

\begin{tabular}{|c|c|c|c|c|c|c||}
\hline Case & $\begin{array}{c}\text { Initial } \\
\text { Critical } \\
\text { Boron(ppm) }\end{array}$ & $\begin{array}{c}\text { Axial } \\
\text { (peak/av) }\end{array}$ & $\mathbf{F}_{\mathbf{\Delta h}} \mathbf{}^{\left({ }^{*}\right)}$ & $\begin{array}{c}\text { Max } \\
\text { Nodal }\end{array}$ & $\left.\mathbf{F}_{\mathbf{Q}}{ }^{*}\right)$ & $\begin{array}{c}\text { Peak } \\
\text { Location } \\
(\mathbf{I , J , K})\end{array}$ \\
\hline $\mathrm{A}$ & 398.7 & 1.39 & $1.84^{1}$ & 2.16 & 2.59 & $(2,1,8)$ \\
\hline $\mathrm{B}$ & 360.3 & 1.38 & $1.78^{2}$ & 2.00 & 2.40 & $(8,1,7)$ \\
\hline $\mathrm{C}$ & 399.7 & 1.39 & $2.36^{1}$ & 2.81 & 3.37 & $(1,2,7)$ \\
\hline $\mathrm{D}$ & 366.2 & 1.38 & $2.10^{1}$ & 2.47 & 2.97 & $(1,2,7)$ \\
\hline $\mathrm{E}$ & 342.0 & 1.38 & $2.35^{1}$ & 2.84 & 3.40 & $(1,8,7)$ \\
\hline $\mathrm{F}$ & 404.4 & 1.39 & $1.79^{1}$ & 2.10 & 2.52 & $(5,6,7)$ \\
\hline $\mathrm{G}$ & 373.9 & 1.38 & $1.91^{1}$ & 2.27 & 2.72 & $(1,8,7)$ \\
\hline $\mathrm{H}$ & 422.1 & 1.40 & $2.50^{1}$ & 2.98 & 3.58 & $(1,2,7)$ \\
\hline $\mathrm{I}$ & 410.6 & 1.39 & $1.92^{1}$ & 2.01 & 2.41 & $(1,6,8)$ \\
\hline
\end{tabular}

(*) Includes rod to assembly peaking factor of 1.2 .

${ }^{1}$ Maximum peaking occurs at beginning of life.

${ }^{2}$ Maximum peaking occurs at $8,000 \mathrm{GWD} / \mathrm{MTU}$. 
Power Distribution Analysis

Table 3.2 Case A Core Performance Parameter Summary

\begin{tabular}{|c|c|c|c|c|c|c|}
\hline $\begin{array}{c}\text { Expos. } \\
\text { (GWD/ } \\
\text { MTU) }\end{array}$ & $\begin{array}{c}\text { Boron } \\
(\mathbf{p p m})\end{array}$ & $\begin{array}{c}\text { Axial } \\
\text { (peak/av) }\end{array}$ & $\begin{array}{c}\mathbf{F}_{\mathbf{\Delta h}} \\
\left(^{*}\right)\end{array}$ & $\begin{array}{c}\text { Max } \\
\text { Nodal }\end{array}$ & $\left.\mathbf{F}_{\mathbf{Q}}{ }^{*}{ }^{*}\right)$ & $\begin{array}{c}\text { Peak } \\
\text { Location } \\
(\mathbf{I , J}, \mathbf{K})\end{array}$ \\
\hline 0.0 & 398.7 & 1.39 & 1.84 & 2.16 & 2.59 & $(2,1,8)$ \\
\hline 0.5 & 369.2 & 1.36 & 1.79 & 2.05 & 2.46 & $(1,2,8)$ \\
\hline 1.0 & 340.7 & 1.34 & 1.74 & 1.95 & 2.34 & $(1,2,8)$ \\
\hline 2.0 & 287.0 & 1.30 & 1.64 & 1.77 & 2.13 & $(1,2,8)$ \\
\hline 3.0 & 239.4 & 1.26 & 1.57 & 1.65 & 1.98 & $(2,3,7)$ \\
\hline 4.0 & 196.8 & 1.23 & 1.58 & 1.63 & 1.95 & $(2,3,7)$ \\
\hline 5.0 & 155.9 & 1.19 & 1.59 & 1.60 & 1.92 & $(2,3,7)$ \\
\hline 6.0 & 112.8 & 1.16 & 1.59 & 1.57 & 1.89 & $(3,3,7)$ \\
\hline 7.0 & 65.7 & 1.14 & 1.63 & 1.58 & 1.90 & $(3,3,7)$ \\
\hline 8.0 & 14.7 & 1.13 & 1.66 & 1.59 & 1.91 & $(3,3,10)$ \\
\hline \hline
\end{tabular}

$\left(^{*}\right)$ Includes rod to assembly peaking factor of 1.2 . 
Table 3.3 Case B Core Performance Parameter Summary

\begin{tabular}{|c|c|c|c|c|c|c|}
\hline $\begin{array}{c}\text { Expos. } \\
\text { (GWD/ } \\
\text { MTU) }\end{array}$ & $\begin{array}{c}\text { Boron } \\
(\mathbf{p p m})\end{array}$ & $\begin{array}{c}\text { Axial } \\
(\text { peak/av) }\end{array}$ & $\left.\mathbf{F}_{\Delta \mathbf{h}}{ }^{*}\right)$ & $\begin{array}{c}\text { Max } \\
\text { Nodal }\end{array}$ & $\mathbf{F}_{\mathbf{Q}}\left(^{*}\right)$ & $\begin{array}{c}\text { Peak } \\
\text { Location } \\
(\mathbf{I}, \mathbf{J}, \mathbf{K})\end{array}$ \\
\hline 0.0 & 360.3 & 1.38 & 1.70 & 2.00 & 2.40 & $(8,1,7)$ \\
\hline 0.5 & 336.4 & 1.36 & 1.62 & 1.84 & 2.21 & $(1,8,7)$ \\
\hline 1.0 & 314.5 & 1.33 & 1.59 & 1.77 & 2.13 & $(3,4,8)$ \\
\hline 2.0 & 275.9 & 1.30 & 1.55 & 1.68 & 2.02 & $(3,4,8)$ \\
\hline 3.0 & 244.6 & 1.27 & 1.57 & 1.67 & 2.00 & $(2,1,7)$ \\
\hline 4.0 & 218.1 & 1.23 & 1.59 & 1.66 & 1.99 & $(1,2,7)$ \\
\hline 5.0 & 190.4 & 1.20 & 1.61 & 1.64 & 1.96 & $(1,2,7)$ \\
\hline 6.0 & 157.0 & 1.16 & 1.62 & 1.67 & 2.00 & $(6,6,7)$ \\
\hline 7.0 & 116.3 & 1.15 & 1.71 & 1.71 & 2.05 & $(6,6,7)$ \\
\hline 8.0 & 69.0 & 1.15 & 1.77 & 1.73 & 2.08 & $(6,6,7)$ \\
\hline
\end{tabular}

(*) Includes rod to assembly peaking factor of 1.2 . 
Power Distribution Analysis

Table 3.4 Case C Core Performance Parameter Summary

\begin{tabular}{|c|c|c|c|c|c|c||}
\hline $\begin{array}{c}\text { Expos. } \\
\text { (GWD/ } \\
\text { MTU) }\end{array}$ & $\begin{array}{c}\text { Boron } \\
(\mathbf{p p m})\end{array}$ & $\begin{array}{c}\text { Axial } \\
\text { (peak/av) }\end{array}$ & $\mathbf{F}_{\mathbf{\Delta h}}\left(^{*}\right)$ & $\begin{array}{c}\text { Max } \\
\text { Nodal }\end{array}$ & $\left.\mathbf{F}_{\mathbf{Q}}{ }^{*}\right)$ & $\begin{array}{c}\text { Peak } \\
\text { Location } \\
(\mathbf{I , J}, \mathbf{K})\end{array}$ \\
\hline 0.0 & 399.7 & 1.39 & 2.36 & 2.81 & 3.37 & $(1,2,7)$ \\
\hline 0.5 & 366.6 & 1.36 & 2.14 & 2.46 & 2.95 & $(1,2,7)$ \\
\hline 1.0 & 336.9 & 1.34 & 1.95 & 2.17 & 2.61 & $(1,2,8)$ \\
\hline 2.0 & 282.2 & 1.29 & 1.64 & 1.74 & 2.09 & $(1,2,8)$ \\
\hline 3.0 & 235.9 & 1.26 & 1.52 & 1.61 & 1.93 & $(1,6,7)$ \\
\hline 4.0 & 197.6 & 1.23 & 1.53 & 1.59 & 1.91 & $(1,6,7)$ \\
\hline 5.0 & 160.6 & 1.20 & 1.54 & 1.57 & 1.88 & $(1,6,7)$ \\
\hline 6.0 & 121.1 & 1.17 & 1.55 & 1.54 & 1.85 & $(1,6,6)$ \\
\hline 7.0 & 76.8 & 1.14 & 1.57 & 1.53 & 1.83 & $(4,4,7)$ \\
\hline 8.0 & 27.5 & 1.14 & 1.61 & 1.55 & 1.87 & $(8,2,6)$ \\
\hline
\end{tabular}

$\left(^{*}\right)$ Includes rod to assembly peaking factor of 1.2 . 
Table 3.5 Case D Core Performance Parameter Summary

\begin{tabular}{|c|c|c|c|c|c|c|}
\hline $\begin{array}{c}\text { Expos. } \\
\text { (GWD/ } \\
\text { MTU) }\end{array}$ & $\begin{array}{c}\text { Boron } \\
\text { (ppm) }\end{array}$ & $\begin{array}{c}\text { Axial } \\
\text { (peak/av) }\end{array}$ & $\mathbf{F}_{\Delta \mathbf{h}}{ }^{\left({ }^{*}\right)}$ & $\begin{array}{c}\text { Max } \\
\text { Nodal }\end{array}$ & $\mathbf{F}_{\mathbf{Q}}{ }^{(*)}$ & $\begin{array}{c}\text { Peak } \\
\text { Location } \\
(\mathbf{I}, \mathbf{J}, \mathbf{K})\end{array}$ \\
\hline 0.0 & 366.2 & 1.38 & 2.10 & 2.47 & 2.97 & $(1,2,7)$ \\
\hline 0.5 & 340.9 & 1.35 & 1.95 & 2.24 & 2.68 & $(1,2,7)$ \\
\hline 1.0 & 317.5 & 1.33 & 1.83 & 2.05 & 2.46 & $(1,2,8)$ \\
\hline 2.0 & 275.6 & 1.30 & 1.63 & 1.75 & 2.09 & $(1,2,8)$ \\
\hline 3.0 & 240.3 & 1.26 & 1.52 & 1.60 & 1.93 & $(2,5,7)$ \\
\hline 4.0 & 210.9 & 1.23 & 1.51 & 1.56 & 1.88 & $(2,5,7)$ \\
\hline 5.0 & 180.2 & 1.20 & 1.51 & 1.52 & 1.83 & $(5,2,7)$ \\
\hline 6.0 & 144.8 & 1.16 & 1.50 & 1.48 & 1.77 & $(5,2,7)$ \\
\hline 7.0 & 103.3 & 1.14 & 1.50 & 1.46 & 1.75 & $(3,3,9)$ \\
\hline 8.0 & 56.3 & 1.14 & 1.53 & 1.48 & 1.77 & $(3,3,11)$ \\
\hline
\end{tabular}

(*) Includes rod to assembly peaking factor of 1.2. 
Power Distribution Analysis

Table 3.6 Case E Core Performance Parameter Summary

\begin{tabular}{|c|c|c|c|c|c|c|}
\hline $\begin{array}{c}\text { Expos. } \\
(\mathbf{G W D} / \\
\mathbf{M T U})\end{array}$ & $\begin{array}{c}\text { Boron } \\
(\mathbf{p p m})\end{array}$ & $\begin{array}{c}\text { Axial } \\
(\mathbf{p e a k} / \mathbf{a v})\end{array}$ & $\left.\mathbf{F}_{\Delta \mathbf{h}} \mathbf{}^{*}\right)$ & $\begin{array}{c}\text { Max } \\
\text { Nodal }\end{array}$ & $\mathbf{F}_{\mathbf{Q}}\left(^{*}\right)$ & $\begin{array}{c}\text { Peak } \\
\text { Location } \\
(\mathbf{I}, \mathrm{J}, \mathrm{K})\end{array}$ \\
\hline 0.0 & 342.0 & 1.38 & 2.35 & 2.84 & 3.40 & $(1,8,7)$ \\
\hline 0.5 & 311.8 & 1.35 & 2.10 & 2.43 & 2.92 & $(1,8,7)$ \\
\hline 1.0 & 288.3 & 1.32 & 1.88 & 2.10 & 2.52 & $(1,8,7)$ \\
\hline 2.0 & 253.1 & 1.29 & 1.58 & 1.71 & 2.06 & $(2,1,7)$ \\
\hline 3.0 & 231.2 & 1.26 & 1.62 & 1.74 & 2.08 & $(1,2,7)$ \\
\hline 4.0 & 218.0 & 1.24 & 1.65 & 1.74 & 2.08 & $(1,2,7)$ \\
\hline 5.0 & 203.8 & 1.20 & 1.67 & 1.72 & 2.06 & $(1,2,7)$ \\
\hline 6.0 & 181.9 & 1.17 & 1.69 & 1.69 & 2.03 & $(3,4,7)$ \\
\hline 7.0 & 149.5 & 1.15 & 1.71 & 1.66 & 2.00 & $(3,4,10)$ \\
\hline 8.0 & 107.6 & 1.15 & 1.71 & 1.67 & 2.00 & $(3,3,11)$ \\
\hline
\end{tabular}

(*) Includes rod to assembly peaking factor of 1.2 . 
Table 3.7 Case F Core Performance Parameter Summary

\begin{tabular}{|c|c|c|c|c|c|c|}
\hline $\begin{array}{c}\text { Expos. } \\
(\mathbf{G W D} / \\
\text { MTU) }\end{array}$ & $\begin{array}{c}\text { Boron } \\
(\mathbf{p p m})\end{array}$ & $\begin{array}{c}\text { Axial } \\
(\text { peak/av) }\end{array}$ & $\left.\mathbf{F}_{\Delta \mathbf{h}}{ }^{*}\right)$ & $\begin{array}{c}\text { Max } \\
\text { Nodal }\end{array}$ & $\mathbf{F}_{\mathbf{Q}}\left(^{*}\right)$ & $\begin{array}{c}\text { Peak } \\
\text { Location } \\
(\mathbf{I}, \mathbf{J}, \mathbf{K})\end{array}$ \\
\hline 0.0 & 404.4 & 1.39 & 1.79 & 2.10 & 2.52 & $(5,6,7)$ \\
\hline 0.5 & 373.1 & 1.36 & 1.76 & 2.02 & 2.42 & $(1,2,8)$ \\
\hline 1.0 & 243.1 & 1.34 & 1.73 & 1.94 & 2.33 & $(1,2,8)$ \\
\hline 2.0 & 286.6 & 1.29 & 1.66 & 1.79 & 2.15 & $(1,2,8)$ \\
\hline 3.0 & 237.0 & 1.26 & 1.59 & 1.68 & 2.01 & $(2,3,7)$ \\
\hline 4.0 & 193.2 & 1.23 & 1.61 & 1.65 & 1.99 & $(2,3,7)$ \\
\hline 5.0 & 151.9 & 1.19 & 1.61 & 1.62 & 1.95 & $(2,3,7)$ \\
\hline 6.0 & 109.1 & 1.17 & 1.61 & 1.62 & 1.95 & $(1,8,6)$ \\
\hline 7.0 & 62.5 & 1.14 & 1.69 & 1.70 & 2.04 & $(8,1,6)$ \\
\hline 8.0 & 12.0 & 1.13 & 1.78 & 1.77 & 2.12 & $(8,1,6)$ \\
\hline
\end{tabular}

(*) Includes rod to assembly peaking factor of 1.2 . 
Power Distribution Analysis

Table 3.8 Case G Core Performance Parameter Summary

\begin{tabular}{|c|c|c|c|c|c|c|}
\hline $\begin{array}{c}\text { Expos. } \\
(\text { GWD/ } \\
\text { MTU) }\end{array}$ & $\begin{array}{c}\text { Boron } \\
(\mathbf{p p m})\end{array}$ & $\begin{array}{c}\text { Axial } \\
\text { (peak/av) }\end{array}$ & $\left.\mathbf{F}_{\mathbf{\Delta h}} \mathbf{(}^{*}\right)$ & $\begin{array}{c}\text { Max } \\
\text { Nodal }\end{array}$ & $\mathbf{F}_{\mathbf{Q}}{ }^{*}$ ) & $\begin{array}{c}\text { Peak } \\
\text { Location } \\
(\mathbf{I}, \mathbf{J}, \mathbf{K})\end{array}$ \\
\hline 0.0 & 373.9 & 1.38 & 1.91 & 2.27 & 3.72 & $(1,8,7)$ \\
\hline 0.5 & 345.7 & 1.36 & 1.81 & 2.08 & 2.49 & $(1,2,7)$ \\
\hline 1.0 & 319.8 & 1.33 & 1.76 & 1.97 & 2.36 & $(1,2,8)$ \\
\hline 2.0 & 275.0 & 1.30 & 1.64 & 1.76 & $\cdot 2.11$ & $(1,2,8)$ \\
\hline 3.0 & 239.7 & 1.26 & 1.53 & 1.61 & 1.94 & $(2,3,7)$ \\
\hline 4.0 & 211.0 & 1.23 & 1.58 & 1.65 & 1.98 & $(2,5,7)$ \\
\hline 5.0 & 183.9 & 1.20 & 1.64 & 1.68 & 2.02 & $(2,5,7)$ \\
\hline 6.0 & 151.8 & 1.16 & 1.69 & 1.68 & 2.02 & $(2,5,7)$ \\
\hline 7.0 & 112.1 & 1.15 & 1.72 & 1.66 & 2.00 & $(2,5,8)$ \\
\hline 8.0 & 65.0 & 1.15 & 1.73 & 1.67 & 2.00 & $(2,5,11)$ \\
\hline
\end{tabular}

(*) Includes rod to assembly peaking factor of 1.2 . 
Table 3.9 Case H Core Performance Parameter Summary

\begin{tabular}{|c|c|c|c|c|c|c||}
\hline $\begin{array}{c}\text { Expos. } \\
\text { (GWD/ } \\
\text { MTU) }\end{array}$ & $\begin{array}{c}\text { Boron } \\
(\mathbf{p p m})\end{array}$ & $\begin{array}{c}\text { Axial } \\
\text { (peak/av) }\end{array}$ & $\left.\mathbf{F}_{\Delta \mathbf{h}} \mathbf{(}^{*}\right)$ & $\begin{array}{c}\mathbf{M a x} \\
\text { Nodal }\end{array}$ & $\left.\mathbf{F}_{\mathbf{Q}}{ }^{*}\right)$ & $\begin{array}{c}\text { Peak } \\
\text { Location } \\
(\mathbf{I}, \mathbf{J}, \mathbf{K})\end{array}$ \\
\hline 0.0 & 422.1 & 1.40 & 2.50 & 2.98 & 3.58 & $(1,2,7)$ \\
\hline 0.5 & 382.8 & 1.36 & 2.24 & 2.57 & 3.09 & $(1,2,7)$ \\
\hline 1.0 & 347.0 & 1.34 & 2.02 & 2.25 & 2.69 & $(1,2,8)$ \\
\hline 2.0 & 283.2 & 1.29 & 1.64 & 1.73 & 2.08 & $(2,3,8)$ \\
\hline 3.0 & 232.6 & 1.26 & 1.49 & 1.58 & 1.90 & $(7,2,7)$ \\
\hline 4.0 & 190.8 & 1.23 & 1.52 & 1.59 & 1.90 & $(6,6,7)$ \\
\hline 5.0 & 154.6 & 1.20 & 1.67 & 1.78 & 2.14 & $(6,6,6)$ \\
\hline 6.0 & 116.7 & 1.18 & 1.84 & 1.93 & 2.32 & $(6,6,6)$ \\
\hline 7.0 & 74.2 & 1.15 & 1.96 & 2.01 & 2.41 & $(6,6,6)$ \\
\hline 8.0 & 25.3 & 1.14 & 2.04 & 2.03 & 2.43 & $(6,6,6)$ \\
\hline
\end{tabular}

(*) Includes rod to assembly peaking factor of 1.2 . 
Power Distribution Analysis

Table 3.10 Case I Core Performance Parameter Summary

\begin{tabular}{|c|c|c|c|c|c|c||}
\hline $\begin{array}{c}\text { Expos. } \\
\text { (GWD/ } \\
\text { MTU) }\end{array}$ & $\begin{array}{c}\text { Boron } \\
\text { (ppm) }\end{array}$ & $\begin{array}{c}\text { Axial } \\
\text { (peak/av) }\end{array}$ & $\mathbf{F}_{\Delta \mathbf{h}}\left(^{*}\right)$ & $\begin{array}{c}\text { Max } \\
\text { Nodal }\end{array}$ & $F_{\mathbf{Q}}\left(^{*}\right)$ & $\begin{array}{c}\text { Peak } \\
\text { Location } \\
(\mathbf{I}, \mathbf{J}, \mathbf{K})\end{array}$ \\
\hline 0.0 & 410.6 & 1.39 & 1.71 & 2.01 & 2.41 & $(1,6,8)$ \\
\hline 0.5 & 380.2 & 1.36 & 1.67 & 1.91 & 2.30 & $(1,6,8)$ \\
\hline 1.0 & 350.9 & 1.34 & 1.62 & 1.83 & 2.19 & $(1,6,8)$ \\
\hline 2.0 & 295.6 & 1.30 & 1.54 & 1.67 & 2.01 & $(2,5,8)$ \\
\hline 3.0 & 245.2 & 1.26 & 1.61 & 1.72 & 2.06 & $(1,2,7)$ \\
\hline 4.0 & 200.7 & 1.23 & 1.73 & 1.81 & 2.18 & $(1,2,7)$ \\
\hline 5.0 & 156.4 & 1.19 & 1.83 & 1.88 & 2.26 & $(1,2,6)$ \\
\hline 6.0 & 109.9 & 1.16 & 1.90 & 1.90 & 2.28 & $(1,2,6)$ \\
\hline 7.0 & 58.8 & 1.14 & 1.92 & 1.86 & 2.23 & $(1,2,6)$ \\
\hline 8.0 & 2.66 & 1.14 & 1.92 & 1.84 & 2.20 & $(2,2,10)$ \\
\hline
\end{tabular}

(*) Includes rod to assembly peaking factor of 1.2 .

Table 3.11 Moderator Temperature Coefficient

\begin{tabular}{|c|c|}
\hline $\begin{array}{c}\text { Fuel Burnup } \\
\text { (GWD/MTU) }\end{array}$ & $\begin{array}{c}\text { Moderator Coefficient } \\
\left(\mathbf{p c m} /{ }^{\circ} \mathbf{C}\right)\end{array}$ \\
\hline 0.0 & -19.4 \\
\hline 3.0 & -22.6 \\
\hline 4.0 & -24.0 \\
\hline 7.0 & -29.3 \\
\hline
\end{tabular}




\section{PIUS GD ASSEMBLY DISTRIBUTION RADIAL CONFIGURATION}

CASE A

\begin{tabular}{|c|c|c|c|c|c|c|c|c|}
\hline B & B & & & & & & & \\
\hline C & B & C & B & C & & & & \\
\hline A & B & $A$ & B & B & B & & & \\
\hline B & A & B & A & B & C & $B$ & & \\
\hline A & B & A & B & A & $B$ & $B$ & C & \\
\hline C & A & C & A & B & A & $B$ & $B$ & \\
\hline A & $B$ & A & $C$ & A & B & $A$ & C & \\
\hline B & A & B & A & B & A & $B$ & $B$ & B \\
\hline A & B & A & $C$ & A & B & $A$ & $C$ & B \\
\hline
\end{tabular}

A - $1.35 \%$ Enriched, No Gd

B - $2.31 \%$ Enriched, No Gd

C - $2.31 \%$ Enriched, Axial Zoned Gd

Figure 3.1 
Power Distribution Analysis

\section{PIUS GD ASSEMBLY DISTRIBUTION RADIAL CONFIGURATION}

CASE B

\begin{tabular}{|c|c|c|c|c|c|c|c|c|}
\hline$B$ & C & & & & & & & \\
\hline$B$ & $B$ & $B$ & B & B & & & & \\
\hline$A$ & B & A & B & $B$ & $B$ & & & \\
\hline C & $A$ & C & A & C & B & B & & \\
\hline$A$ & B & $A$ & B & A & C & B & B & \\
\hline B & $A$ & B & $A$ & B & $A$ & $B$ & B & \\
\hline$A$ & C & $A$ & B & A & C & $A$ & B & \\
\hline B & $A$ & C & A & B & $A$ & B & $B$ & C \\
\hline$A$ & $B$ & $A$ & $B$ & A & C & $A$ & B & $B$ \\
\hline
\end{tabular}

A - $1.35 \%$ Enriched, No Gd

B - $2.31 \%$ Enriched, No Gd

C - $2.31 \%$ Enriched, Axial Zoned Gd

Figure 3.2 


\section{PIUS GD ASSEMBLY DISTRIBUTION RADIAL CONFIGURATION}

CASE C

\begin{tabular}{|c|c|c|c|c|c|c|c|c|}
\hline B & B & & & & & & & \\
\hline C & B & C & B & C & & & & \\
\hline A & B & $A$ & B & $B$ & B & & & \\
\hline B & $A$ & B & $A$ & B & B & B & & \\
\hline$A$ & C & A & C & $A$ & B & B & C & \\
\hline B & $A$ & B & $A$ & $C$ & $A$ & $B$ & B & \\
\hline A & $B$ & A & B & A & B & $A$ & $C$ & \\
\hline B & A & B & $A$ & $C$ & A & B & B & B \\
\hline$A$ & $B$ & $A$ & $B$ & $A$ & $B$ & A & C & $B$ \\
\hline
\end{tabular}

A - $1.35 \%$ Enriched, No Gd

B - $2.31 \%$ Enriched, No Gd

C - $2.31 \%$ Enriched, Axial Zoned Gd

Figure 3.3 
Power Distribution Analysis

\section{PIUS GD ASSEMBLY DISTRIBUTION RADIAL CONFIGURATION}

CASE D

\begin{tabular}{|c|c|c|c|c|c|c|c|c|}
\hline B & $B$ & & & & & & & \\
\hline B & B & $B$ & $B$ & B & & & & \\
\hline A & C & A & $C$ & B & $C$ & & & \\
\hline B & $A$ & $B$ & A & B & B & C & & \\
\hline A & B & A & B & $A$ & $B$ & $B$ & B & \\
\hline C & A & C & A & B & $A$ & C & $B$ & \\
\hline$A$ & B & A & $C$ & A & $B$ & $A$ & B & \\
\hline B & A & $B$ & $A$ & B & $A$ & C & B & B \\
\hline$A$ & B & $A$ & C & A & $B$ & $A$ & $B$ & B \\
\hline
\end{tabular}

A - $1.35 \%$ Enriched, No Gd

B - $2.31 \%$ Enriched, No Gd

C - $2.31 \%$ Enriched, Axial Zoned Gd

Figure 3.4 
Power Distribution Analysis

\section{PIUS GD ASSEMBLY DISTRIBUTION RADIAL CONFIGURATION}

CASE E

\begin{tabular}{|c|c|c|c|c|c|c|c|c|}
\hline B & $B$ & & & & & & & \\
\hline B & B & B & B & B & & & & \\
\hline A & B & $A$ & C & B & $B$ & & & \\
\hline B & $A$ & B & $A$ & $B$ & C & B & & \\
\hline A & C & A & C & $A$ & B & B & B & \\
\hline B & $A$ & B & $A$ & C & $A$ & C & B & \\
\hline A & C & $A$ & B & A & B & A & B & \\
\hline B & $A$ & $C$ & $A$ & C & $A$ & B & B & B \\
\hline A & $B$ & $A$ & B & A & B & A & B & $B$ \\
\hline
\end{tabular}

A - $1.35 \%$ Enriched, No Gd

B - $2.31 \%$ Enriched, No Gd

C - $2.31 \%$ Enriched, Axial Zoned Gd

Figure 3.5 
Power Distribution Analysis

\section{PIUS GD ASSEMBLY DISTRIBUTION RADIAL CONFIGURATION}

CASE F

\begin{tabular}{|c|c|c|c|c|c|c|c|}
\hline B & B & & & & & & \\
\hline B & C & B & C & B & & & \\
\hline A & B & $A$ & B & B & C & & \\
\hline B & $A$ & B & A & $B$ & B & C & \\
\hline A & $B$ & $A$ & B & $A$ & B & B & B \\
\hline C & A & C & A & $B$ & $A$ & B & C \\
\hline$A$ & B & A & C & $A$ & B & A & B \\
\hline B & $A$ & B & A & $B$ & $A$ & $B$ & C \\
\hline A & $B$ & A & C & $A$ & B & A & B \\
\hline
\end{tabular}

A - $1.35 \%$ Enriched, No Gd

B - $2.31 \%$ Enriched, No Gd

C - $2.31 \%$ Enriched, Axial Zoned Gd

Figure 3.6 


\section{PIUS GD ASSEMBLY DISTRIBUTION RADIAL CONFIGURATION}

CASE G

\begin{tabular}{|c|c|c|c|c|c|c|c|c|}
\hline B & B & & & & & & & \\
\hline B & B & B & B & C & & & & \\
\hline A & $B$ & $A$ & B & B & B & & & \\
\hline C & A & C & A & B & C & B & & \\
\hline A & $B$ & $A$ & B & $A$ & $B$ & $B$ & C & \\
\hline C & A & C & A & B & A & B & B & \\
\hline A & B & $A$ & C & A & C & $A$ & B & \\
\hline B & $A$ & $B$ & $A$ & B & $A$ & $B$ & B & B \\
\hline$A$ & $B$ & A & $C$ & $A$ & C & A & $B$ & $B$ \\
\hline
\end{tabular}

A - $1.35 \%$ Enriched, No Gd

B - $2.31 \%$ Enriched, No Gd

C - $2.31 \%$ Enriched, Axial Zoned Gd

Figure 3.7 
Power Distribution Analysis

\section{PIUS GD ASSEMBLY DISTRIBUTION RADIAL CONFIGURATION}

CASE H

\begin{tabular}{|c|c|c|c|c|c|c|c|c|}
\hline B & C & & & & & & & \\
\hline$B$ & $B$ & B & B & C & & & & \\
\hline$A$ & B & $A$ & $B$ & B & B & & & \\
\hline C & $A$ & C & A & C & $B$ & B & & \\
\hline$A$ & $B$ & $A$ & B & A & $C$ & $B$ & $C$ & \\
\hline$B$ & A & $B$ & $A$ & B & A & $B$ & $B$ & \\
\hline A & $B$ & A & $B$ & A & C & $A$ & $B$ & \\
\hline$B$ & $A$ & B & $A$ & $B$ & A & $B$ & $B$ & $C$ \\
\hline A & $B$ & A & B & A & C & A & B & B \\
\hline
\end{tabular}

A - $1.35 \%$ Enriched, No Gd

B - 2.31\% Enriched, No Gd

C - $2.31 \%$ Enriched, Axial Zoned Gd

Figure 3.8 


\section{PIUS GD ASSEMBLY DISTRIBUTION RADIAL CONFIGURATION}

CASE I

\begin{tabular}{|c|c|c|c|c|c|c|c|}
\hline$B$ & C & & & & & & \\
\hline B & B & $B$ & B & C & & & \\
\hline$A$ & B & A & B & B & B & & \\
\hline B & $A$ & C & A & B & C & B & \\
\hline A & $B$ & A & B & $A$ & B & $B$ & C \\
\hline B & $A$ & B & A & B & $A$ & $B$ & B \\
\hline A & $C$ & A & B & A & C & A & B \\
\hline B & $A$ & C & A & B & $A$ & $B$ & B \\
\hline$A$ & B & A & B & $A$ & B & $A$ & B \\
\hline
\end{tabular}

A - $1.35 \%$ Enriched, No Gd

B - $2.31 \%$ Enriched, No Gd

C - $2.31 \%$ Enriched, Axial Zoned Gd

Figure 3.9 
Power Distribution Analysis

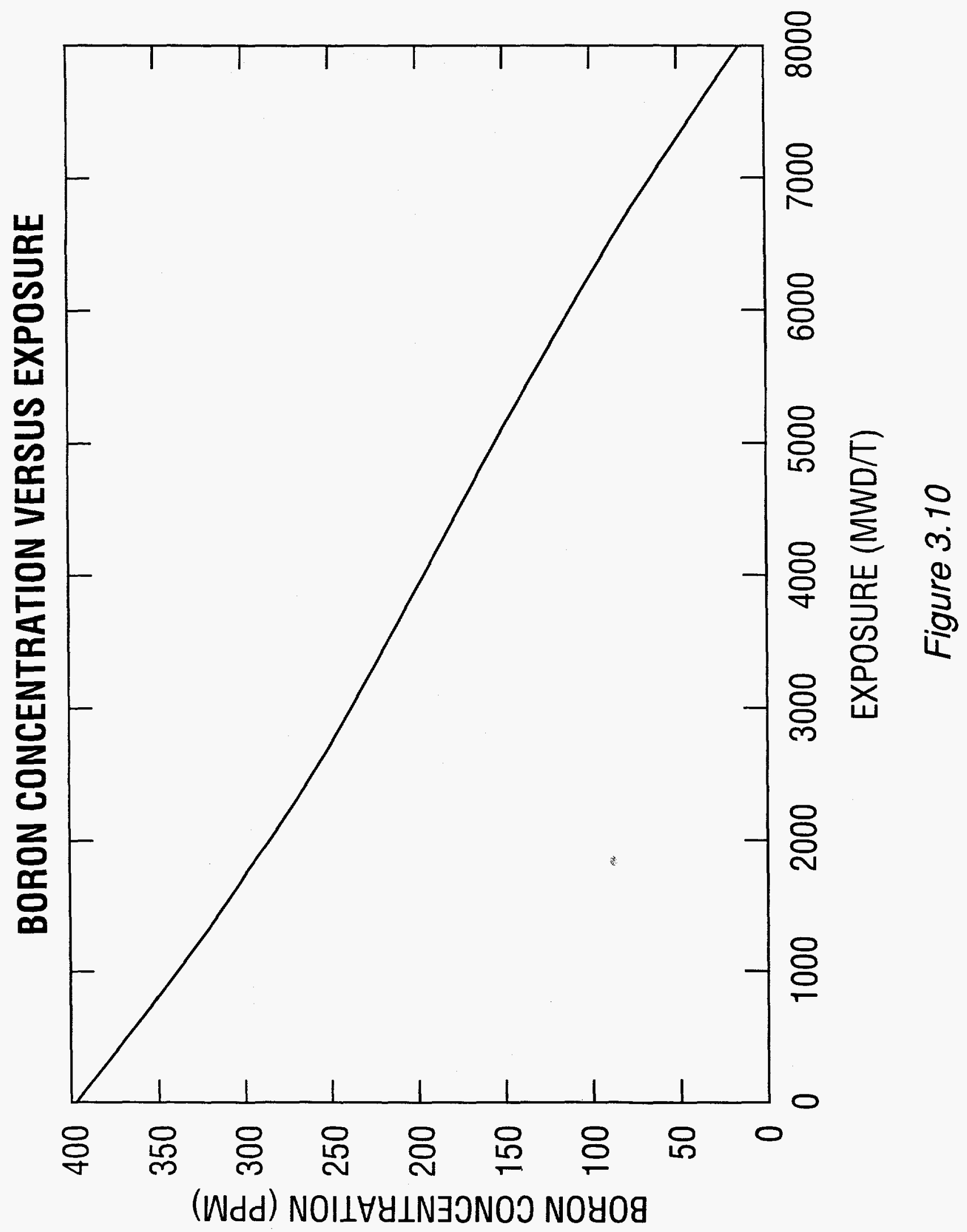




\section{ASSEMBLY RELATIVE POWER AT 0.0 MWD/T EXPOSURE}

\begin{tabular}{|c|c|c|c|c|c|c|c|}
\hline 0.459 & & & & & & & \\
\hline 0.945 & 0.528 & 0.638 & 0.344 & & & & \\
\hline 1.285 & 0.972 & 1.198 & 1.074 & 0.557 & & & \\
\hline 1.187 & 1.354 & 1.148 & 1.286 & 0.769 & 0.557 & & \\
\hline 1.329 & 1.071 & 1.340 & 1.164 & 1.286 & 1.074 & 0.344 & \\
\hline 0.952 & 0.810 & 0.950 & 1.340 & 1.148 & 1.198 & 0.638 & \\
\hline 1.324 & 0.943 & 0.810 & 1.071 & 1.354 & 0.972 & 0.528 & \\
\hline 1.267 & 1.324 & 0.952 & 1.329 & 1.187 & 1.285 & 0.945 & 0.459 \\
\hline 1.531 & 1.114 & 0.848 & 1.083 & 1.386 & 1.036 & 0.712 & 0.502 \\
\hline 2 & 3 & 4 & 5 & 6 & 7 & 8 & 9 \\
\hline
\end{tabular}

Figure 3.11 
Power Distribution Analysis

\section{ASSEMBLY RELATIVE POWER AT 500 MWD/T EXPOSURE}

\begin{tabular}{|c|c|c|c|c|c|c|c|c|c|}
\hline 9 & 0.522 & 0.470 & & & & & & & \\
\hline 8 & 0.759 & 0.956 & 0.552 & 0.639 & 0.351 & & & & \\
\hline 7 & 1.032 & 1.268 & 0.963 & 1.176 & $\mid 1.056$ & 0.562 & & & \\
\hline 6 & 1.362 & 1.168 & 1.328 & 1.128 & 1.267 & 0.806 & 0.562 & & \\
\hline 5 & 1.085 & 1.319 & 1.070 & 1.323 & 1.147 & 1.267 & 1.056 & 0.351 & \\
\hline 4 & 0.911 & 0.973 & 0.873 & 0.968 & 1.323 & 1.128 & 1.176 & 0.639 & \\
\hline 3 & 1.112 & 1.318 & 0.965 & 0.873 & 1.070 & 1.328 & 0.963 & 0.552 & \\
\hline 2 & 1.488 & 1.241 & 1.318 & 0.973 & 1.319 & 1.168 & $\mid 1.268$ & 0.956 & 0.470 \\
\hline 1 & 1.314 & 1.488 & 1.112 & 0.911 & 1.085 & 1.362 & 1.032 & 0.759 & 0.522 \\
\hline
\end{tabular}

Figure 3.12 


\section{ASSEMBLY RELATIVE POWER AT 2000 MWD/T EXPOSURE}

\begin{tabular}{|c|c|c|c|c|c|c|c|c|c|}
\hline 9 & 0.585 & 0.503 & & & & & & & \\
\hline 8 & 0.896 & 0.989 & 0.620 & 0.639 & 0.371 & & & & \\
\hline 7 & 1.015 & 1.212 & 0.929 & 1.105 & 1.005 & 0.579 & & & \\
\hline 6 & 1.286 & 1.105 & 1.249 & 1.065 & 1.214 & 0.904 & 0.579 & & \\
\hline 5 & 1.090 & 1.288 & 1.072 & 1.273 & 1.093 & 1.214 & 1.005 & 0.371 & \\
\hline 4 & 1.090 & 1.047 & 1.061 & 1.029 & 1.273 & 1.065 & 1.105 & 0.639 & \\
\hline 3 & 1.114 & 1.305 & 1.044 & 1.061 & 1.072 & 1.249 & 0.929 & 0.620 & \\
\hline 2 & 1.370 & 1.170 & 1.305 & 1.047 & 1.288 & 1.105 & 1.212 & 0.989 & 0.503 \\
\hline 1 & 1.195 & 1.370 & 1.114 & 1.090 & 1.090 & 1.286 & 1.015 & 0.896 & 0.585 \\
\hline & 1 & 2 & 3 & 4 & 5 & 6 & 7 & 8 & 9 \\
\hline
\end{tabular}

Figure 3.13 
Power Distribution Analysis

\section{ASSEMBLY RELATIVE POWER AT 4000 MWD/T EXPOSURE}

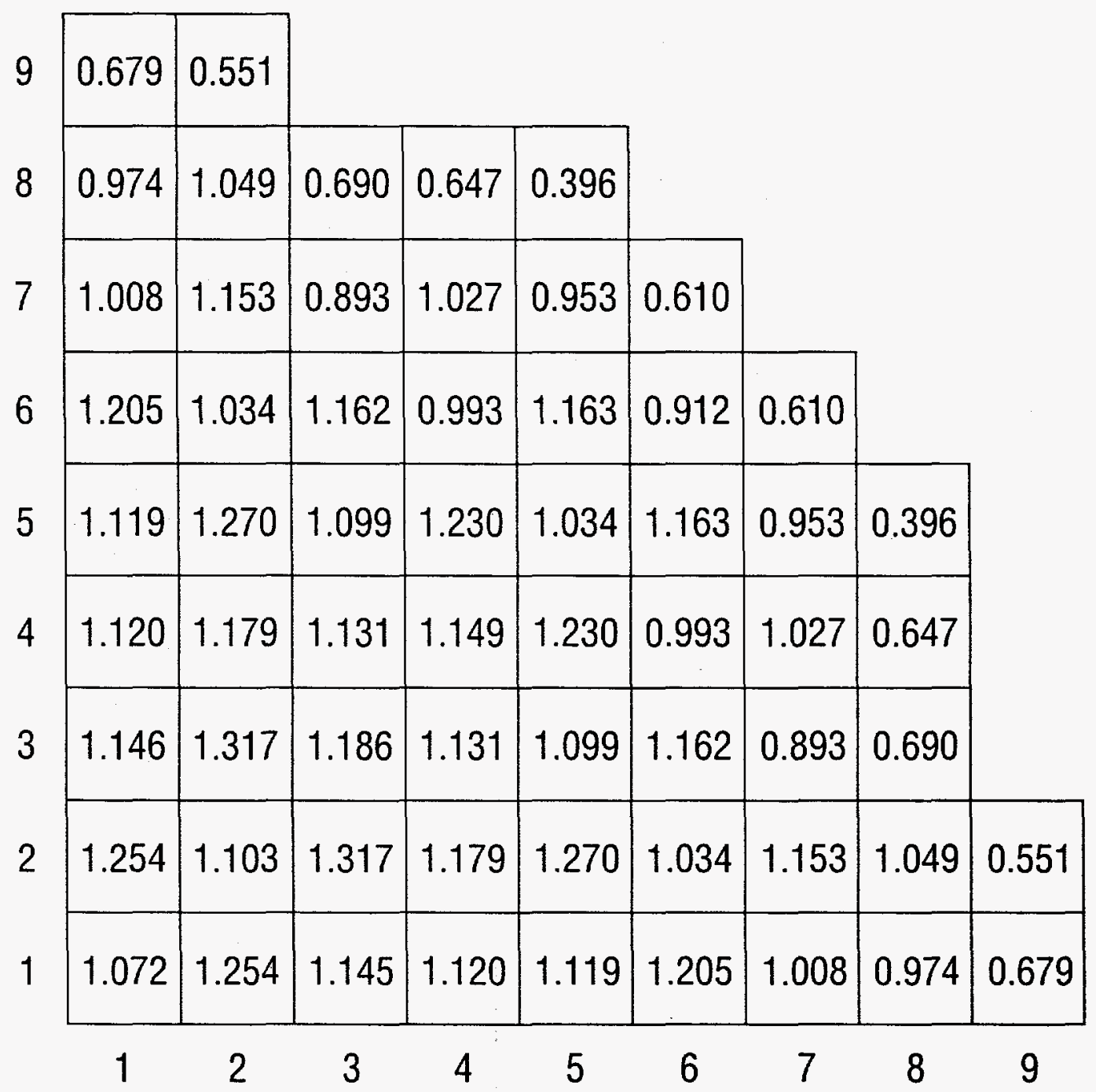

Figure 3.14 


\section{ASSEMBLY RELATIVE POWER AT 6000 MWD/T EXPOSURE}

\begin{tabular}{|c|c|c|c|c|c|c|c|c|}
\hline 0.793 & 0.612 & & & & & & & \\
\hline 0.890 & 1.146 & 0.709 & 0.685 & 0.427 & & & & \\
\hline 1.037 & 1.137 & $\mid 0.892$ & 0.993 & 0.938 & 0.655 & & & \\
\hline 1.160 & 0.993 & 1.116 & 0.955 & 1.150 & 0.793 & $0.655 \mid$ & & \\
\hline 1.156 & 1.267 & 1.145 & 1.215 & 1.005 & 1.150 & 0.938 & 0.427 & \\
\hline 0.927 & 1.303 & 0.958 & 1.278 & 1.215 & 0.955 & 0.993 & 0.685 & \\
\hline 1.180 & 1.328 & 1.321 & 0.958 & 1.145 & 1.116 & 0.892 & 0.709 & \\
\hline 1.169 & 1.051 & 1.328 & 1.303 & $1.267 \mid$ & 0.993 & 1.137 & 1.146 & 0.612 \\
\hline 0.982 & 1.169 & 1.180 & 0.927 & 1.156 & 1.160 & 1.037 & 0.890 & 0.793 \\
\hline
\end{tabular}

Figure 3.15 
Power Distribution Analysis

\section{ASSEMBLY RELATIVE POWER AT 8000 MWD/T EXPOSURE}

\begin{tabular}{|c|c|c|c|c|c|c|c|c|c|}
\hline 9 & 0.906 & 0.678 & & & & & & & \\
\hline 3 & 0.761 & 1.260 & 0.676 & 0.755 & 0.460 & & & & \\
\hline 7 & 1.089 & 1.153 & 0.926 & 1.001 & 0.960 & 0.714 & & & \\
\hline 6 & 1.135 & 0.972 & 1.094 & 0.944 & 1.167 & 0.670 & 0.714 & & \\
\hline 5 & 1.169 & 1.247 & $\mid 1.169$ & 1.199 & 0.994 & 1.167 & 0.960 & $\mid 0.460$ & \\
\hline 4 & 0.721 & 1.361 & 0.750 & 1.350 & 1.199 & 0.944 & 1.001 & 0.755 & \\
\hline 3 & 1.178 & 1.302 & 1.384 & 0.750 & 1.169 & 1.094 & 0.926 & $\mid 0.676$ & \\
\hline 2 & 1.092 & 0.995 & 1.302 & 1.361 & 1.247 & 0.972 & 1.153 & 1.260 & 0.678 \\
\hline 1 & 0.910 & 1.092 & 1.178 & 0.721 & 1.169 & 1.135 & 1.089 & 0.761 & 0.905 \\
\hline
\end{tabular}

Figure 3.16 


\section{PEAK/AVERAGE POWER VERSUS EXPOSURE}

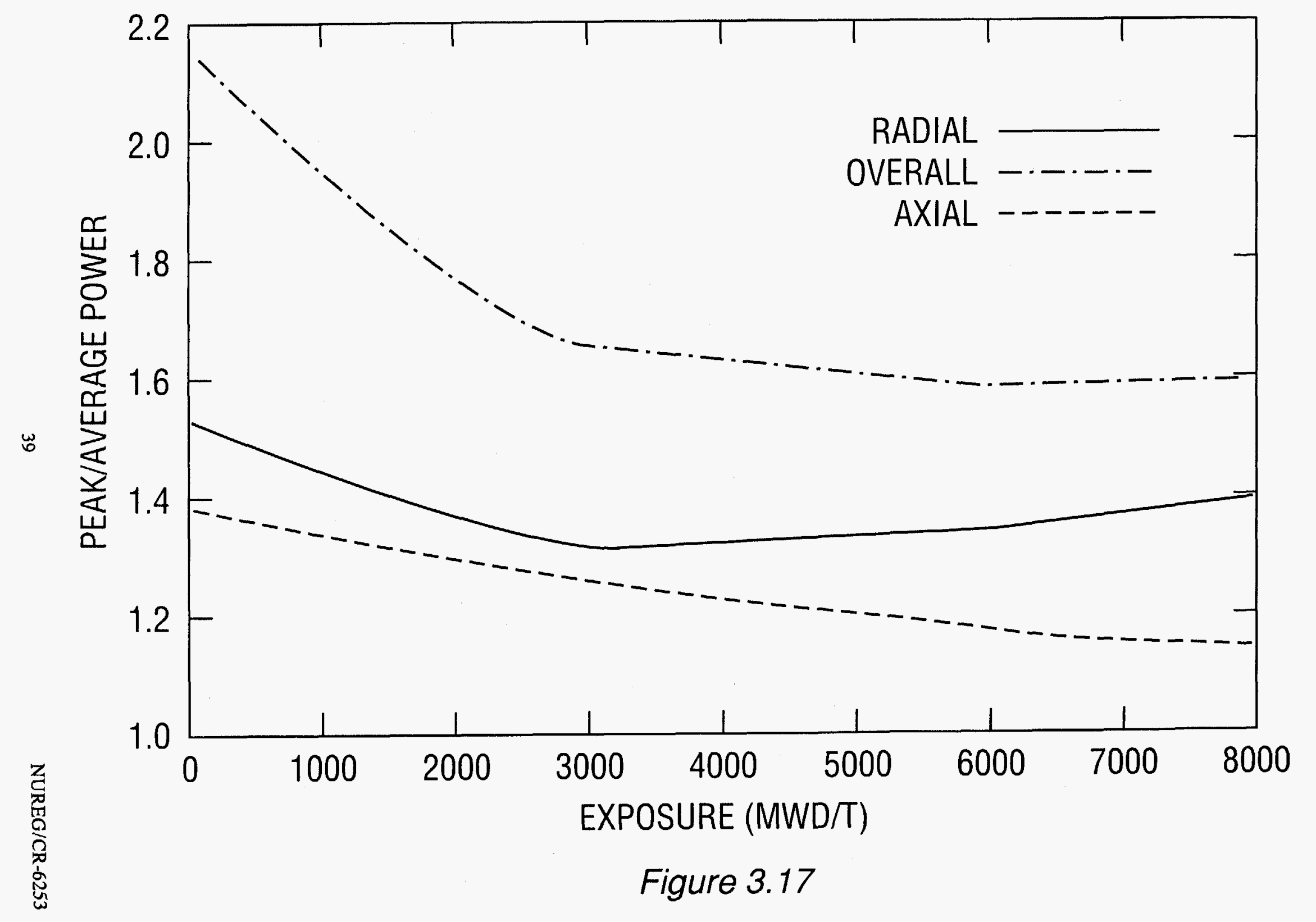




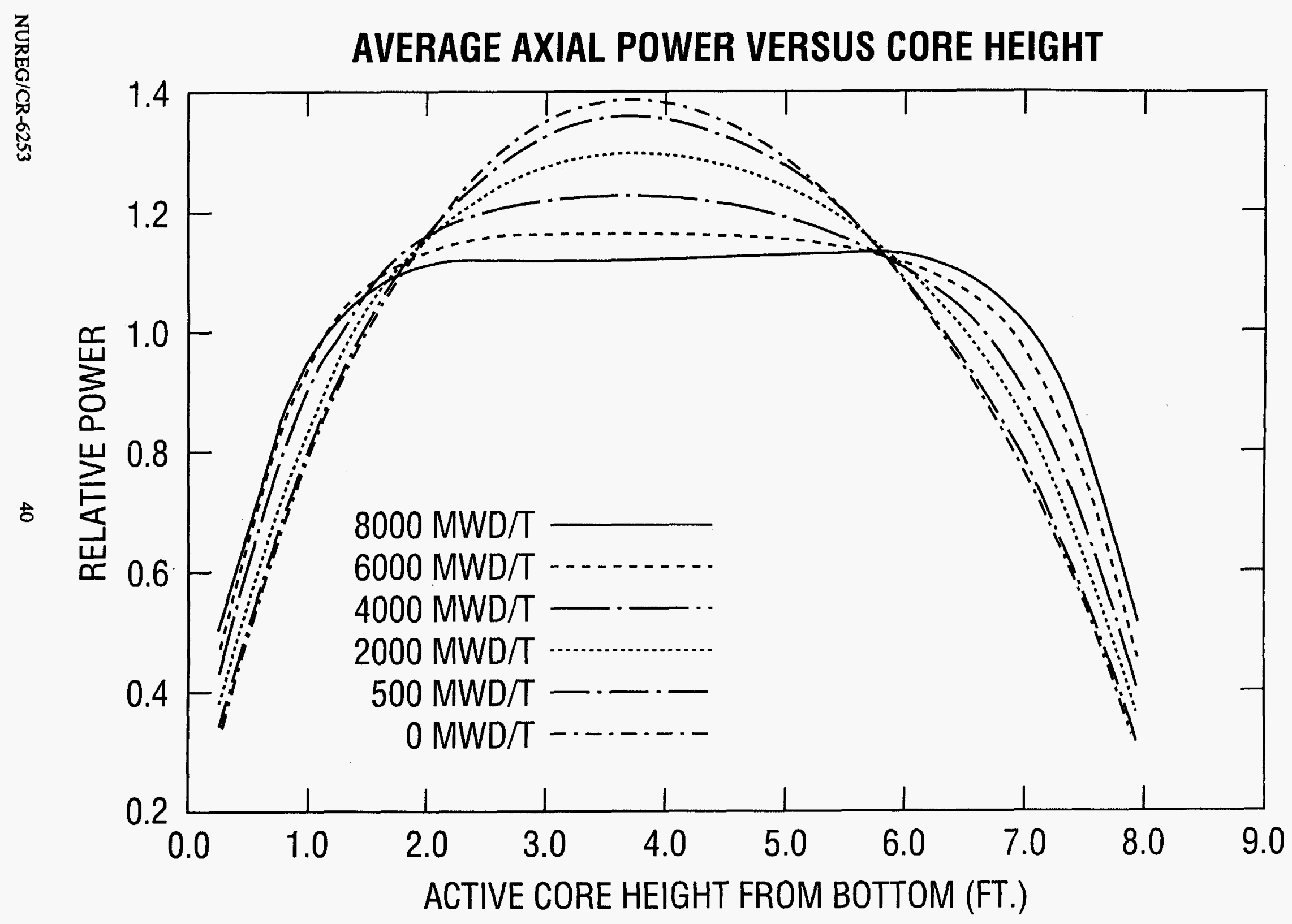

Figure 3.18 
Power Distribution Analysis

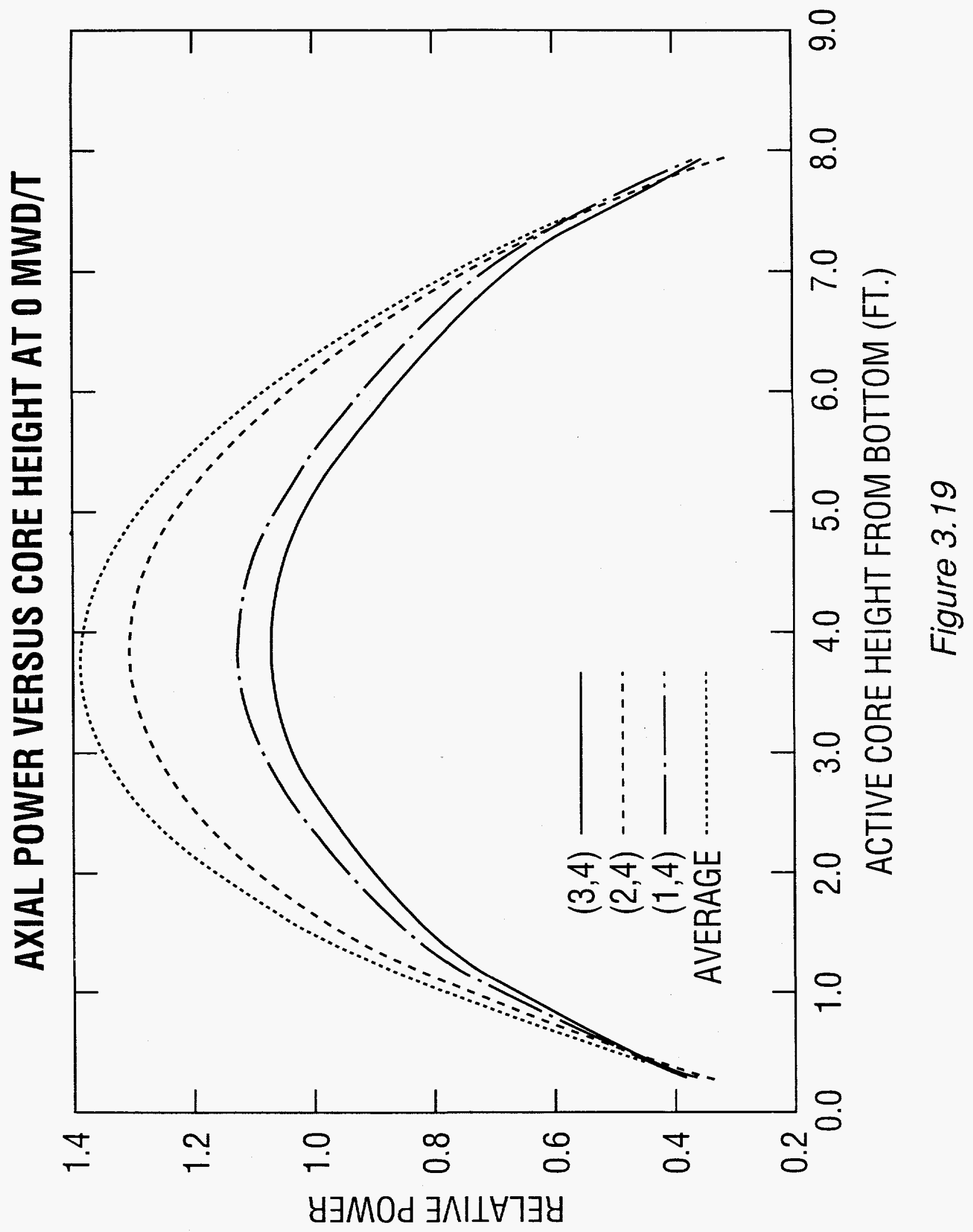


Power Distribution Analysis

\section{ASSEMBLY EXPOSURE AT 500 MWD/T}

\begin{tabular}{|c|c|c|c|c|c|c|c|c|c|}
\hline & 250.8 & 229.6 & & & & & & & \\
\hline & 356.1 & 472.6 & 264.1 & 319.1 & 172.1 & & & & \\
\hline & 518.1 & 642.7 & 486.2 & 599.2 & 536.9 & 278.5 & & & \\
\hline ; & 693.1 & 593.5 & 676.9 & 574.1 & 642.8 & 384.4 & 278.5 & & \\
\hline 5 & 541.6 & 664.3 & 535.4 & 670.2 & 582.1 & 642.8 & 536.9 & 172.1 & \\
\hline 4 & 424.1 & 475.8 & 405.1 & 475.1 & 670.2 & 574.1 & 599.2 & 319.1 & \\
\hline 3 & 557.1 & 662.1 & 471.4 & 405.1 & 535.4 & 676.9 & 486.2 & 264.1 & \\
\hline$?$ & 765.6 & 633.4 & 662.1 & 475.8 & 664.3 & 593.5 & 642.7 & 472.6 & 229.6 \\
\hline & 679.0 & 765.6 & 557.1 & 424.1 & 541.6 & $\mid 693.1$ & 518.1 & 356.1 & 250.8 \\
\hline & 1 & 2 & 3 & 4 & 5 & 6 & 7 & 8 & 9 \\
\hline
\end{tabular}

Figure 3.20 


\section{ASSEMBLY EXPOSURE AT 2000 MWD/T}

\begin{tabular}{|c|c|c|c|c|c|c|c|c|c|}
\hline & 1054. & 945.8 & & & & & & & \\
\hline & 1542. & 1917. & 1115. & 1277. & 705.2 & & & & \\
\hline & 2060. & 2526. & 1919. & 2338. & 2103. & 1127. & & & \\
\hline & 2711. & 2325. & 2642. & 2245. & 2525. & 1630. & 1127. & & \\
\hline & 2170 & 2632. & 2141. & 2637. & 2284. & 2525. & 2103. & 705.2 & \\
\hline & 1857. & 1959. & 1782. & 1945. & 2637. & 2245 . & 2338. & 1277. & \\
\hline & 2227. & 2635. & 1944. & 1782. & 2141. & 2642. & 1919. & 1115. & \\
\hline$?$ & 2959. & 2472. & 2635. & 1959. & 2632. & 2325 . & 2526 . & 1917. & 945.8 \\
\hline & 2612. & 2959. & 2227. & 1857. & 2170 & 2711. & 2060. & 1542. & 1054. \\
\hline & 1 & 2 & 3 & 4 & 5 & 6 & 7 & 8 & 9 \\
\hline
\end{tabular}

Figure 3.21 


\section{ASSEMBLY EXPOSURE AT 4000 MWD/T}

\begin{tabular}{|c|c|c|c|c|c|c|c|c|c|}
\hline 9 & 2268. & 1975. & & & & & & & \\
\hline 8 & 3396 . & 3920. & 2395. & 2557. & 1458. & & & & \\
\hline 7 & 4083. & 4916. & 3756 . & 4504. & 4082. & 2298. & & & \\
\hline 6 & 5239. & 4497. & 5091. & 4335. & 4920. & 3464. & 2298. & & \\
\hline 5 & 4361. & 5195. & 4293. & 5155. & 4435. & 4920. & 4082. & 1458. & \\
\hline 4 & 4096 . & 4115. & 3979. & 4058. & 5155. & 4335. & 4504. & 2557. & \\
\hline 3 & 4470. & 5249. & 4099. & 3979. & 4293. & 5091. & 3756 . & 2395. & \\
\hline 2 & 5639. & 4778. & 5249. & 4115. & 5195. & 4497. & 4916. & 3920. & 1975. \\
\hline 1 & 4939. & 5639. & 4470. & 4096. & 4361. & 5239. & 4083. & 3396. & 2268. \\
\hline & 1 & 2 & 3 & 4 & 5 & 6 & 7 & 8 & 9 \\
\hline
\end{tabular}

Figure 3.22 


\section{ASSEMBLY EXPOSURE AT 6000 MWD/T}

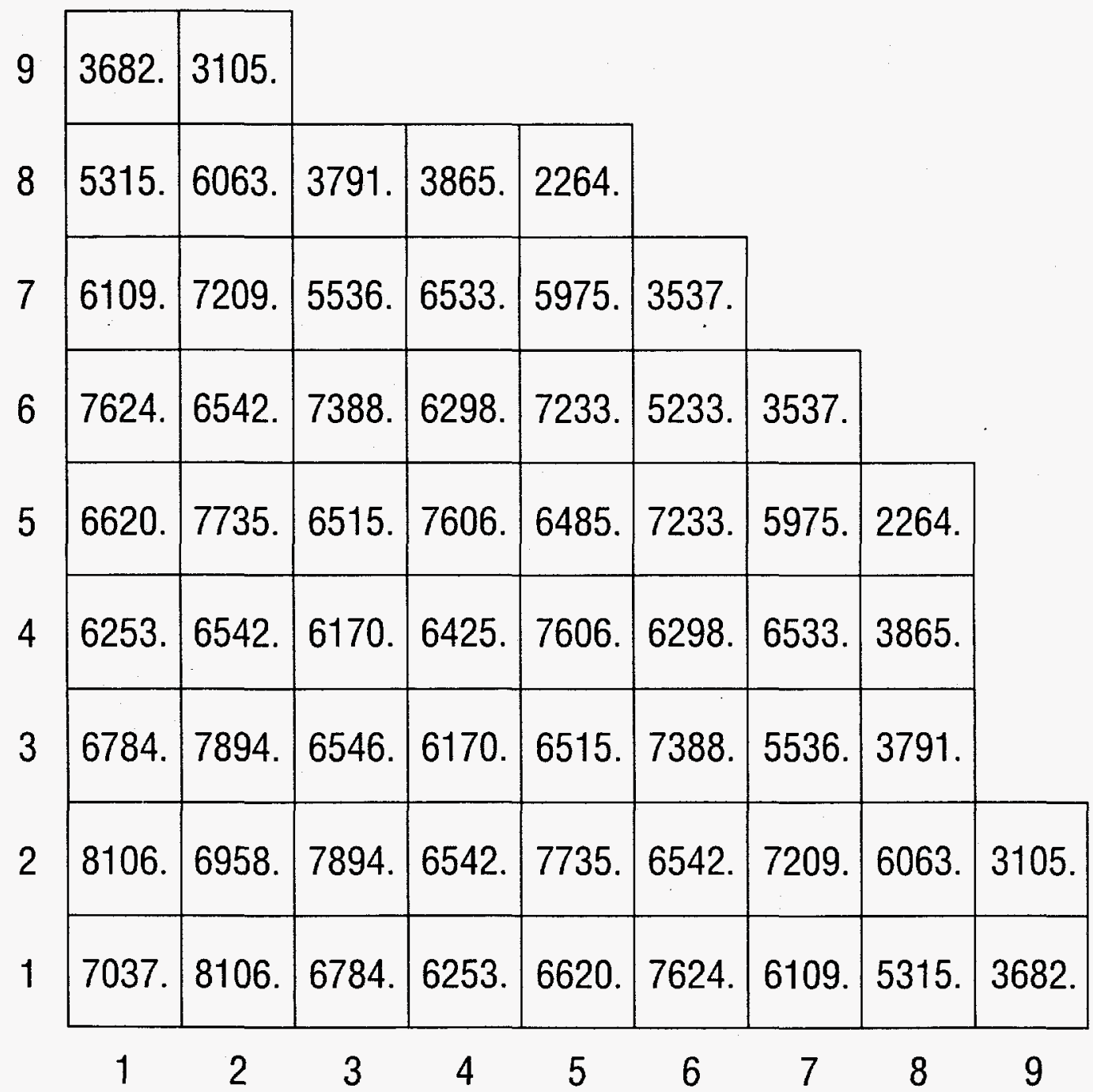

Figure 3.23 
Power Distribution Analysis

\section{ASSEMBLY EXPOSURE AT 8000 MWD/T}

\begin{tabular}{|c|c|c|c|c|c|c|c|c|}
\hline 5325. & 4362. & & & & & & & \\
\hline 7029. & 8412. & 5197. & 5266. & 3134. & & & & \\
\hline 8208. & 9489. & 7334. & 8519. & 7858. & 4875. & & & \\
\hline 9931. & 8517. & 9607. & 8200. & 9539. & 6755. & 4875. & & \\
\hline 8943. & 10260. & 8821. & 10030. & 8488. & 9539. & 7858. & 3134. & \\
\hline 7999. & 9185. & 7978. & 9025. & 10030. & 8200 & 8519. & 5266. & \\
\hline 9147. & 10540. & 8228. & 7978. & 8821. & 9607. & 7334. & 5197. & \\
\hline 10400. & 8031. & 10540. & 8185. & 10260 & 8517. & 9489. & 8412. & 4362. \\
\hline 8961. & 10400 & 8147. & 7999. & 8943. & 9931. & 8208. & 7029. & 5325. \\
\hline 1 & 2 & 3 & 4 & 5 & 6 & 7 & 8 & 9 \\
\hline
\end{tabular}

Figure 3.24 


\section{Scram Reactivity Analysis}

\subsection{Introduction}

The scram reactivity analysis includes a series of parametric calculations which determine the reactivity effects associated with the use of the flow of soluble boron through a set of density locks for reactor control/scram. The analysis employed the NODE-P2 model to calculate the effect of selected input boron flow distributions on the core reactivity. Reactivity effects of the time-dependent spatial boron distributions resulting from several assumed variations in the mass flow rates from the boron pool were considered. The effect of the reduced pool water temperature on the reactivity coefficient was examined and found to be relatively small. Both beginning and end-of-cycle conditions were analyzed. The results of this analysis are described in the following sections.

\subsection{Calculational Methodology}

\subsubsection{Reactivity Analysis}

A series of parametric calculations were performed to determine the core reactivity for a set of assumed timedependent input boron flows. The high-concentration boron coolant enters the core when the density locks open in response to a reactor upset. The boron pool water contains $2200 \mathrm{ppm}$ soluble boron and is maintained at $122^{\circ} \mathrm{F}$, while the reactor coolant contains less than 400 ppm soluble boron and is maintained at an inlet temperature of $500^{\circ} \mathrm{F}$. The boron pool flow is assumed to mix uniformly with the reactor coolant system flow before entering the bottom of the core. In this study, several boron distributions were determined by representing the time-dependent mass flow from the boron pool as a linear ramp or a square-wave pulse. The reactivity was evaluated as the boron flows up through the core by performing a series of steady-state analyses for the sequential instantaneous three-dimensional boron distributions. In this study the boron distributions were assumed to be uniform in the horizontal plane and varied only axially.

\subsubsection{Determination of the Core Boron Distribution}

The boron flow through the core was determined by assuming the coolant velocity was the same in all fuel assemblies and independent of the neutronic feedback.
The effect of the colder pool water on the scram reactivity was included by varying the inlet subcooling. The calculations were performed in two steps: (1) the inlet subcooling was held constant at the value corresponding to the initial reactor coolant system temperature, and (2) the inlet subcooling varied with the mass flow rate from the boron pool, resulting in a decreasing inlet coolant temperature. It is important to note that the reactivity effects determined in this study are parametrized in terms of the calculated boron distributions. Consequently, the assumptions made in calculating the boron distributions only affect the range of distributions considered, and not the relationship between the scram reactivity and the boron distribution.

\subsubsection{Boron Reactivity Coefficient}

In the PIUS design, an upset in the core operating conditions is expected to result in the opening of the lower density locks and the flow of the highly borated pool water into the core. The increase in coolant boron concentration provides the required negative control/scram reactivity. The instantaneous boron reactivity coefficient $\alpha_{B}(t)$ is defined

$$
\alpha_{B}(t)=\Delta \rho(t) / \Delta B(t),
$$

where the change in core reactivity $\Delta \rho(t)$ is

$$
\Delta \rho(t)=\left[k_{e f f}(t)-k_{e f f}(o)\right] / k_{e f f}(o),
$$

and $k_{\text {eff }}(t)$ is the instantaneous core multiplication. The core-average boron concentration is defined as an average of the local boron concentration over the core volume $\mathrm{V}$

$$
B(t)=\frac{1}{V} \int B(\underline{x}, t) d \underline{x} .
$$

In the analysis of situations involving nonlinear flow it will be convenient to define the boron reactivity coefficient in terms of the spatially weighted boron concentration

$$
B_{w}(t)=\int P(\underline{x}, t) B(\underline{x}, t) d \underline{x},
$$

where $P(x, t)$ is the normalized core power distribution. This importance weighting of the local boron concentration accounts for the reduced (increased) effectiveness of the boron poison in the regions of low 
(high) neutron flux. If the boron concentration is uniform then $B_{w}=B$, and the core-average spatially weighted boron concentration is independent of the power distribution.

It is important to note that the modeling of the scram reactivity simplifies greatly when the core-wide reactivity coefficient $\alpha_{B}$ is not a function of the reactor statepoint so that $\alpha_{B}(t)=$ constant.

\subsection{Analysis Results and Discussion}

A series of three-dimensional neutronic core analyses has been performed to determine the reduction in core reactivity as a result of the injection of highly borated 2000-ppm pool water during a reactor scram. ${ }^{\text {a }}$ Calculations were performed for both a linear ramp injection and a square-wave pulse injection of pool water. In the linear ramp injection, the borated pool flow is taken to be a time-dependent fraction $\alpha$ t of the reactor coolant flow. Ramp rates of $\alpha=0.05,0.10$, and 0.15 , corresponding to 5,10 , and $15 \%$ pool flow per second, were considered. In the square-wave pulse scram injection, the fraction of reactor coolant flow from the borated pool increases instantaneously from zero to $\beta$ for a period of 1.2 seconds (approximately two-thirds of the core transit time). Pulse heights of $\beta=0.10$, and 0.15 were considered.

In Figure 4.1, the scram reactivity $\rho$ is plotted versus coreaverage boron concentration for the $\alpha=0.10$ case in which the pool fraction of the coolant flow increases as $\alpha \mathrm{t}$ $=0.10 \mathrm{t}$. The scram reactivity exhibits a linear dependence on the core-average boron concentration $B$ with the time-independent boron reactivity coefficient $\alpha_{B}$ given by the slope of the $\rho(B)$ curve. The boron reactivity coefficient determined by fitting the data of Figure 4.1 is $\alpha_{\mathrm{B}}=-1.31 \times 10^{-2}(\% \Delta \mathrm{k} / \mathrm{k}) / \mathrm{ppm}$ (Table 4.1$)$.

In Figure 4.2, the scram reactivity $\rho$ is presented for the three $\alpha=0.05,0.10$, and 0.15 linear ramp pool flow cases. Again, the core reactivity resulting from the boron injection is a linear function of the core-average boron concentration $B$ and is characterized by a constant boron coefficient $\alpha_{\mathrm{B}}$. The boron coefficients for these cases are given in Table 4.1 and are seen to increase from -1.36 to -

\footnotetext{
Since the inserted reactivity is calculated as a function of boron concentration, the slightly larger 2200 -ppm boron concentration of the PIUS pool water has a negligible effect on the conclusions of the present study.
}

$1.26 \times 10^{-2}(\% \Delta \mathrm{k} / \mathrm{k}) / \mathrm{ppm}$ as the ramp rate increases from $\alpha=0.05$ to $\alpha=0.15$. This increase in the boron coefficient for the higher ramp rates is due to the fact that in these cases the boron distribution is peaked more toward the bottom of the core and away from the highimportance regions near the core midplane.

The borated pool water is at a reduced temperature of $122^{\circ} \mathrm{F}$ relative to the $500^{\circ} \mathrm{F}$ core inlet temperature. Consequently, the reduced temperature of the pool provides a positive reactivity contribution to the scram reactivity. In order to estimate this effect, a calculation was performed in which the core inlet temperature was reduced based on the instantaneous pool flow and an assumed pool temperature of $250^{\circ} \mathrm{F}$. Since NODE-P2 calculations were performed in the steady-state mode, the coolant temperatures at all axial locations are based on the instantaneous inlet temperature and are, therefore, lower than the physical situation in which the higher elevation temperatures are based on earlier and warmer inlet temperatures. This approximation results in an overprediction of the effect of the cooler pool temperature. In Figure 4.3, the scram reactivity $\rho$ is presented as a function of boron concentration for an $\alpha$ $=0.15$ linear ramp for both a constant $500^{\circ} \mathrm{F}$ inlet temperature and a reduced pool inlet temperature of $250^{\circ} \mathrm{F}^{\mathrm{b}}$ Based on these results it is concluded that the cooler $122^{\circ} \mathrm{F}$ pool inlet temperature will result in a relatively small decrease in the scram reactivity.

The reactivity worth of the boron injection increases with core life due to the depletion of the gadolinium, which results in a reduction in gadolinium thermal absorption and a more thermal spectrum. Both of these effects tend to increase the reactivity effect of the boron poison. The scram reactivity versus boron concentration is presented in Figure 4.4 for the $\alpha=0.10$ pool flow case for both beginning-of-cycle (BOC) and end-of-cycle (EOC) conditions and indicates the linear behavior observed in the earlier ramp flow calculations. In Table 4.1 the boron reactivity coefficient is seen to decrease from -1.31 to $1.45 \times 10^{-2}(\% \Delta \mathrm{k} / \mathrm{k}) / \mathrm{ppm}$ from BOC to EOC conditions.

\footnotetext{
The slight initial increase in reactivity in the case of the reduced inlet temperature (curve with the solid triangles) is a result of the (approximate) use of the instantaneous cooler inlet temperatures for all axial elevations in the steady-state calculation. As a result, the average core coolant temperature is always slightly cooler than in the actual situation where the temperature of the coolant at the top of the core is determined by an earlier and warmer inlet temperature.
} 
The BOC and EOC reduced-inlet-temperature cases are also presented in Figure 4.4 and indicate a more positive pool-water-temperature reactivity effect for EOC conditions. This is a result of the more negative EOC temperature coefficient due to the reduced gadolinium absorption and a more thermal spectrum.

The axial distributions of the coolant boron concentration are relatively smooth for the linear ramp pool flow injection. For the $\alpha=0.15$ linear ramp injection, the local boron concentration increases linearly by $\sim 400 \mathrm{ppm}$ over the height of the core. In order to evaluate the effects of the strong spatial variations in the core boron concentration several square-wave pulse cases were calculated. In the $\beta=\mathbf{0 . 1 5}$ pool flow pulse, the boron concentration increases from 400 to $640 \mathrm{ppm}$ across the front of the square-wave pulse.

The scram reactivity $\rho$ for the $\beta=0.15$ pulse is presented in Figure 4.5. The values of scram reactivity $\rho$ when the center of the pulse is in the bottom of the core $\left(\mathrm{z}_{\mathrm{P}}<0.5 \mathrm{H}\right)$ and in the top of the core $\left(\mathrm{z}_{\mathrm{P}}>0.5 \mathrm{H}\right)$ are indicated separately. The boron worth is reduced when the pulse is in the bottom of the core due to the reduced neutron flux and importance of this region relative to the axial locations close to the core midplane. Additionally, as the boron pulse moves from the bottom of the core to the core midplane the axial flux distribution shifts away from the poison and towards the top of the core. This axial redistribution of the flux further reduces the differential boron scram reactivity. In Figure 4.5 , it is seen that as the pulse approaches the core midplane the flux redistribution is complete and the pulse begins to enter the high-flux region increasing the differential scram worth. (This is analogous to the effect produced by control rod insertion which results in the typical scram $S$ curve). Relative to the uniform case, the differential poison worth is reduced by more than a factor of two at the bottom of the core and is increased by $\sim 15 \%$ at the core midplane. ${ }^{c}$ From Figure 4.5 it is also seen that the scram reactivity is essentially symmetric about the core midplane, with a slightly larger reactivity insertion when the pulse is in the bottom of the core. This is due to the

\footnotetext{
c It is noteworthy that a similar variation in differential boron worth may also be expected for corresponding radial variations in the boron poison concentration.
}

reduced coolant temperature which results in increased axial peaking and a more thermal spectrum.

In order to quantify the effect of the spatial boron distribution further, the core-average spatially weighted boron concentration $B_{w}$ was determined. As defined in Equation (4), $\mathrm{B}_{\mathrm{w}}$ is determined by weighting the local boron concentration with the instantaneous power distribution. In Figure 4.6, the boron scram reactivity is plotted versus the power-weighted boron concentration $\mathrm{B}_{\mathrm{w}}$ for the pool flow $\alpha=0.10$ linear ramp and the $\beta=$ 0.10 and $\beta=0.15$ pulse boron injections. It is evident that when the boron scram reactivity is determined using the power-weighted boron concentration via $\rho\left(\mathrm{B}_{\mathrm{w}}\right)$, a constant core-wide boron coefficient $\alpha_{B}$ is obtained. In Table 4.1 the boron coefficients for these cases are presented and range from -1.34 to $-1.50 \times 10^{-2}$ $(\% \Delta \mathrm{k} / \mathrm{k}) / \mathrm{ppm}$.

It is noteworthy that the Table 4.1 boron coefficient for the $\alpha=0.10$ ramp flow injection only changes by $\sim 3 \%$ when defined in terms of the power-weighted boron concentration $B_{w}$. This approximate equivalence of the $\rho\left(\mathrm{B}_{\mathrm{w}}\right)$ and $\rho(\mathrm{B})$ curves for the linear ramp injection implies that $B_{w}=B$. This, in fact, follows from the resulting linear dependence of the local boron concentration

$$
B(z)=B+B_{1}\left(z-z_{m}\right)
$$

where $B$ is the core-average concentration and $z_{m}$ is the elevation of the core midplane. ${ }^{d}$ Since $P(z)$ is (to a good approximation) even about the core midplane and $\mathrm{B}(\mathrm{z})$ is odd, the Equation (4) integral of the linear term in Equation (5) vanishes, and the weighted-boron $\mathrm{B}_{\mathrm{w}}=\mathrm{B}$ and is independent of the power distribution. Consequently, for pool flows $W_{p}(t)$ that increase linearly $\left(\mathrm{W}_{\mathrm{p}}=\alpha \mathrm{t}\right)$ over the core coolant transit time $\Delta \tau$ (i.e., $\left.\Delta \tau^{(\mathrm{n}-1)} \mathrm{W}_{\mathrm{p}}^{(\mathrm{n})} \ll \mathrm{W}_{\mathrm{p}}^{(1)}\right)$, the local boron concentration varies linearly over the height of the core and the scram reactivity may be described with a constant core-wide boron reactivity coefficient $\alpha_{\mathrm{B}}$. In this case, a pointkinetics modelling of the boron scram may be used in PIUS transient analyses.

\footnotetext{
This linear dependence of $B(z)$ assumes that the core flow velocity is constant during the scram. If the flow velocity varies significantly some error will be introduced into the inferred $\alpha_{B}$.
} 
Table 4.1 Boron Reactivity Coefficients ${ }^{+}$

\begin{tabular}{|c|c|c|c|}
\hline $\begin{array}{l}\text { Type of } \\
\text { Pool Flow }\end{array}$ & Fuel Burnup & $\begin{array}{c}\text { Spatially } \\
\text { Weighted } \\
\text { Boron }\end{array}$ & $\begin{array}{c}\text { Boron Reactivity } \\
\text { Coefficient } \alpha_{B}{ }^{*} \\
\left(\mathbf{1 0} 0^{-2}(\% \Delta \mathrm{k} / \mathrm{k}) / \mathrm{ppm}\right)\end{array}$ \\
\hline Ramp, $\alpha=0.05$ & $\mathrm{BOC}$ & no & -1.36 \\
\hline $\operatorname{Ramp}, \alpha=0.10$ & $\mathrm{BOC}$ & no & -1.31 \\
\hline $\operatorname{Ramp}, \alpha=0.15$ & $\mathrm{BOC}$ & no & -1.26 \\
\hline Ramp, $\alpha=0.10$ & EOC & no & -1.45 \\
\hline Ramp, $\alpha=0.10$ & $\mathrm{BOC}$ & yes & -1.34 \\
\hline Ramp, $\alpha=0.10$ & $\mathrm{EOC}$ & yes & -1.50 \\
\hline Pulse, $\beta=0.10$ & BOC & yes & -1.48 \\
\hline Pulse, $\beta=0.15$ & BOC & yes & -1.50 \\
\hline
\end{tabular}

+ In all of these calculations the inlet temperature was held constant.

* Because of the unavailability of detailed PIUS core design data at the time of this study, assumptions were required in the modeling and loading of the Gd fuel and these specific values of $\alpha_{\mathrm{B}}$ depend to a certain extent on these assumptions. 


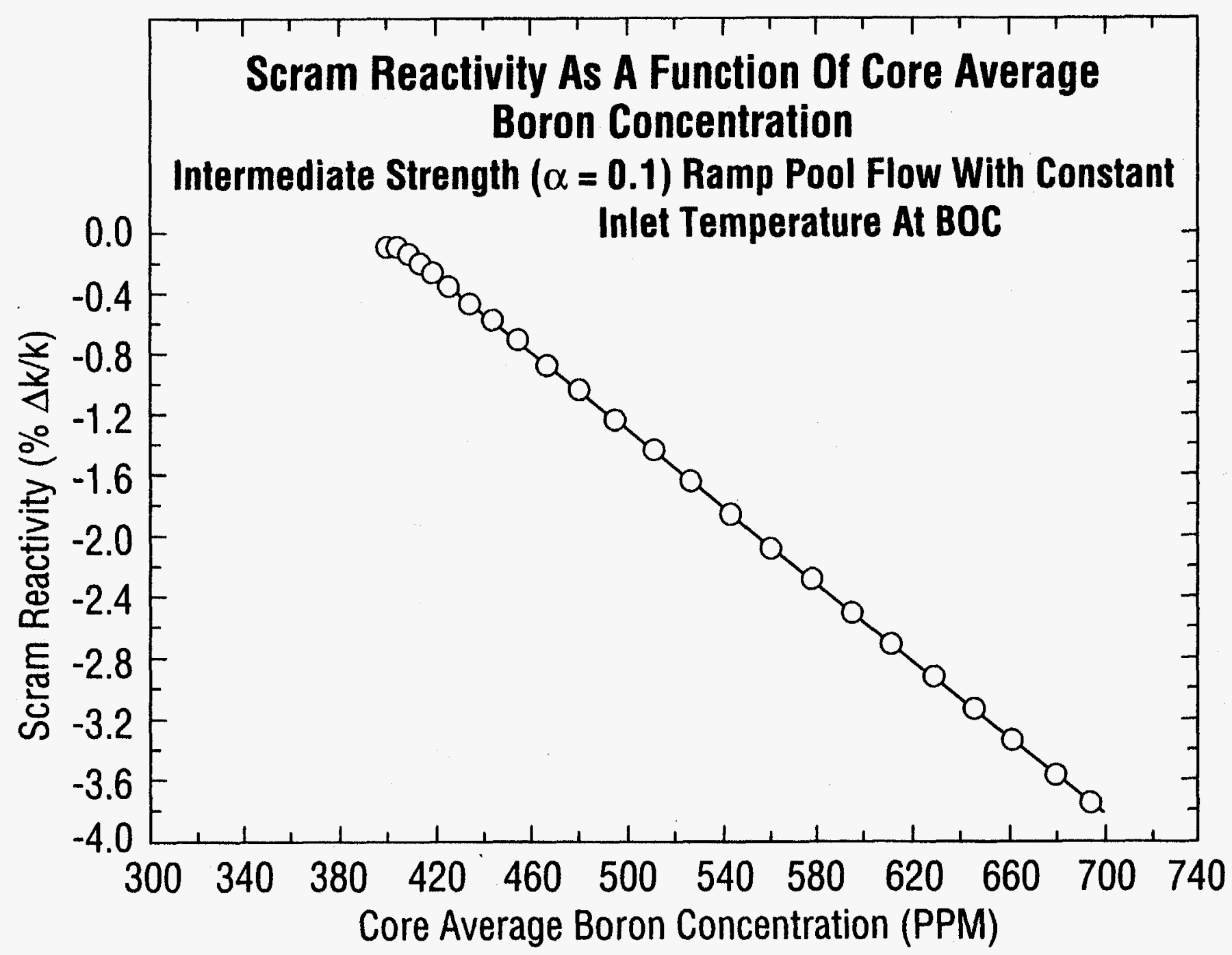

Figure 4.1 
Scram Reactivity Analysis

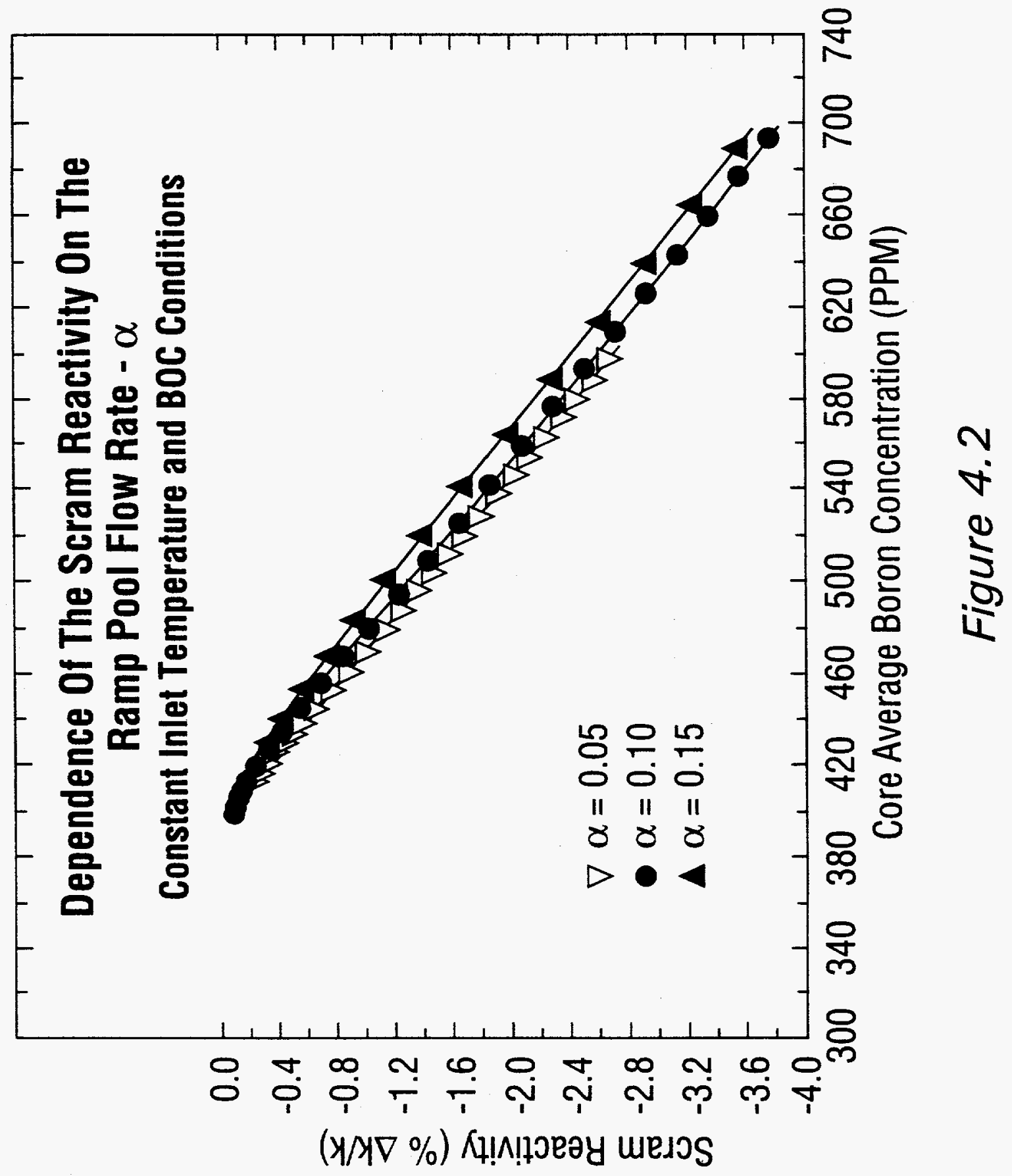




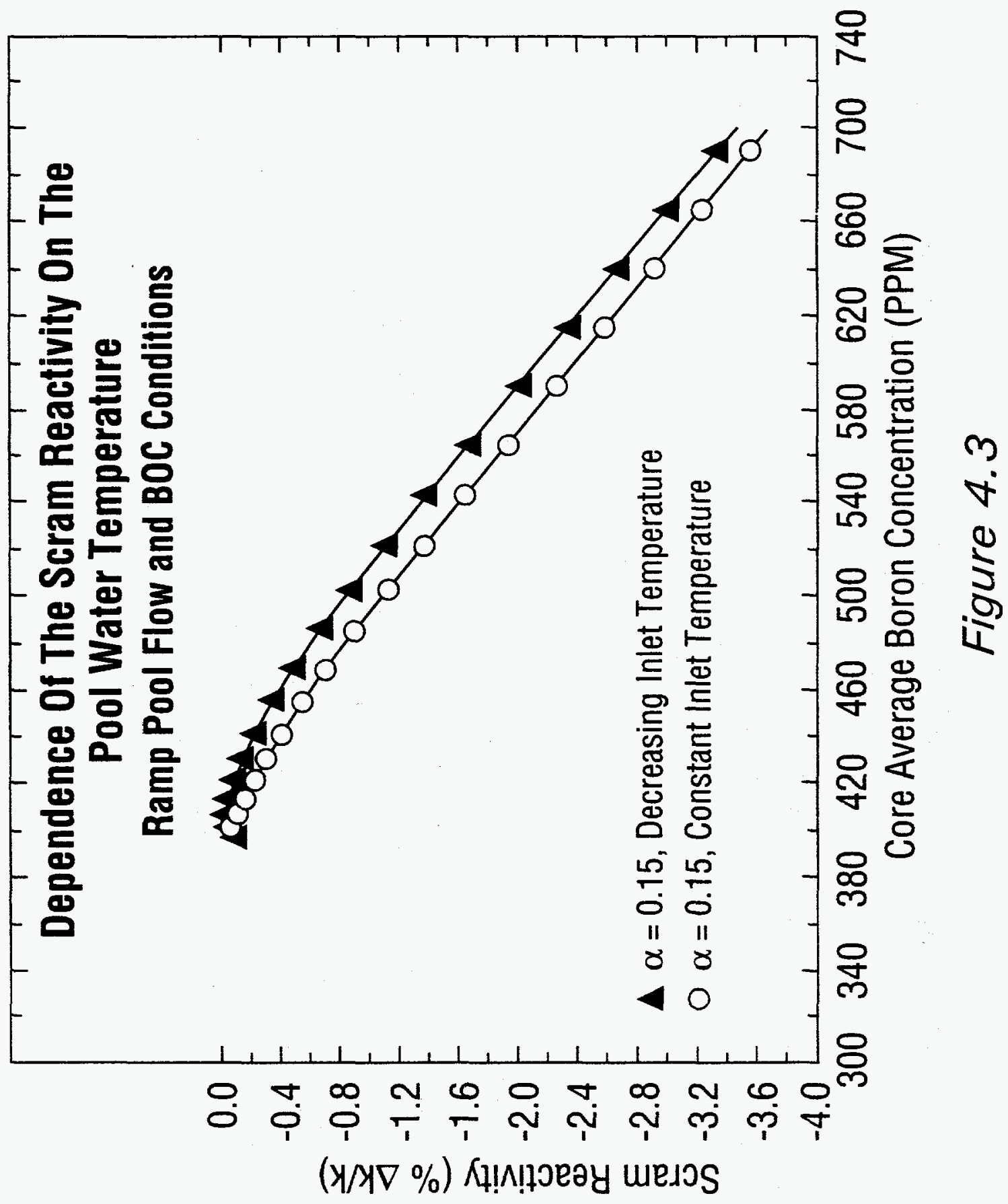




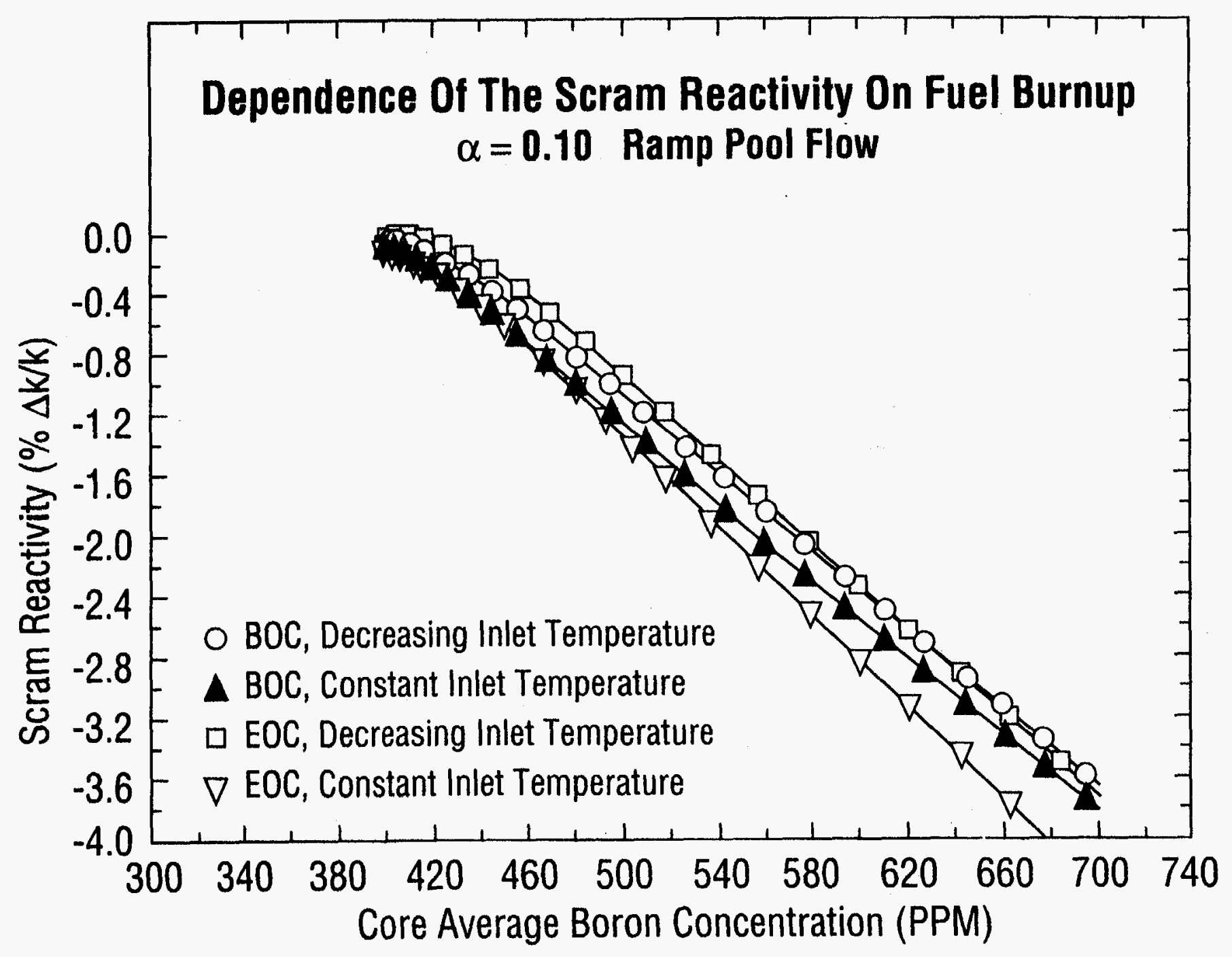

Figure 4.4 


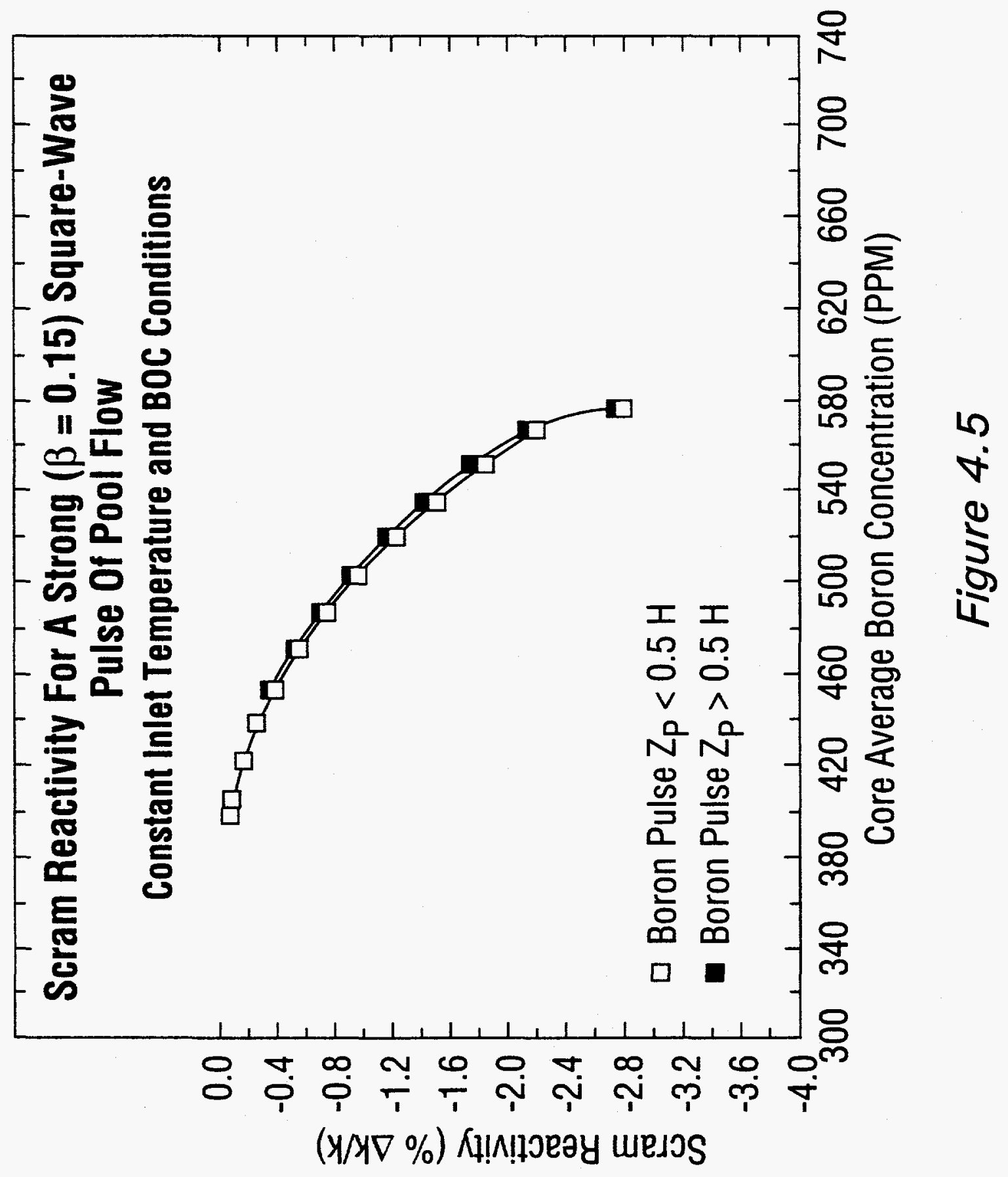




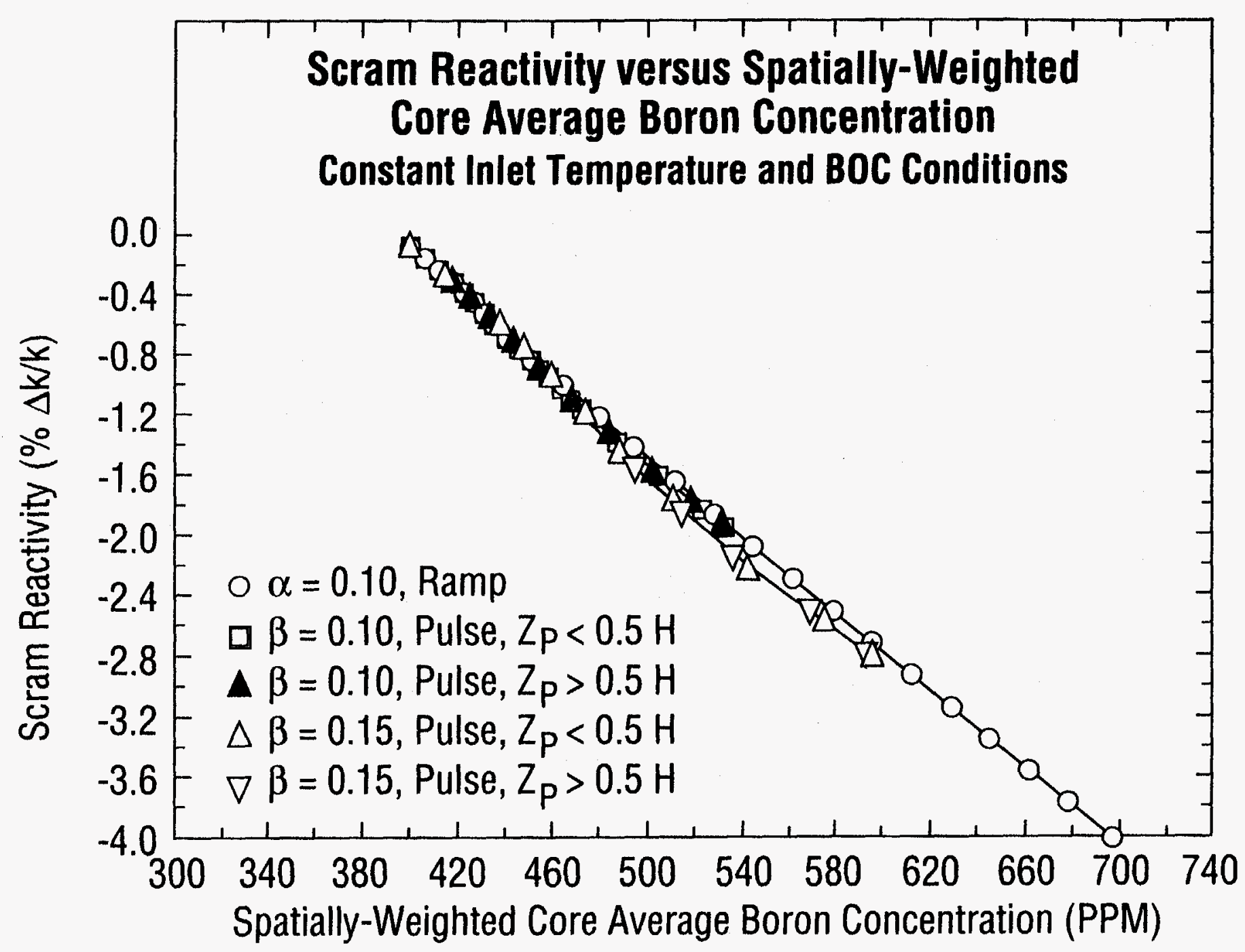

Figure 4.6 


\section{Summary and Conclusions}

A series of core coupled neutronic/thermal-hydraulic analyses have been performed for the PIUS reactor core design. The calculation models and analyses are based on the information provided in the PIUS Preliminary Safety Information Document (PSID). The calculational model employed the CPM lattice physics code to determine the fuel assembly nuclear data as a function of the local fuel exposure, moderator density, boron concentration and fuel temperature. The core model is based on the NODE-P2 neutronics/thermal-hydraulics code. The analyses included an evaluation of (1) the local power peaking and margin to fuel limits and (2) the scram reactivity resulting from the injection of soluble boron through the lower density locks.

The PIUS design does not provide scram/control rods for balancing local reactivity changes during the fuel-burnup cycle and allow active control of the power density. Consequently, the burnup dependent power distribution and local margin to fuel limits is determined by the fuel design and initial core loading. Assuming the fuel design given in the PSID, detailed core depletion calculations have been performed for a representative set of nine initial core loadings and the three-dimensional core power distributions have been determined. These calculations indicate that the PIUS radial $F_{\Delta h}$ and total $F_{Q}$ power peaking is significantly stronger (and the resulting margin to fuel limits significantly less) than the values provided in the PSID.

A parametric analysis has been performed to characterize the scram reactivity for the PIUS design. Threedimensional NODE-P2 calculations of the core multiplication $\boldsymbol{k}_{\text {eff }}$ have been performed to determine the scram reactivity resulting from the flow of the highly borated pool water into the core. Both linear ramp and square-wave pulse boron pool flows have been considered. The boron distributions considered were uniform in the horizontal plane.

For the linear ramp pool flows considered, the boron distributions increase linearly with core height and the spatially weighted boron concentration is independent of the core power distribution, allowing the scram reactivity to be characterized by a constant core-wide boron reactivity coefficient. For the square-wave pulse pool flows, the boron distributions include strong spatial variability and the scram reactivity can not be described using a unique boron reactivity coefficient. However, when the local boron concentration is weighted with the instantaneous power distribution, the scram reactivity can be described in terms of a single constant boron reactivity coefficient.

The boron reactivity coefficient was found to be $\sim 10 \%$ larger at the end-of-cycle than at the beginning-of-cycle, and the positive reactivity effect of the lower-temperature pool water was found to be relativcly small.

These calculations suggest that for pool flows which increase linearly, the inserted reactivity is independent of the power distribution and the scram reactivity can be described by a constant core-wide reactivity coefficient $\alpha_{B}$, allowing a point-kinetics description of the scram. However, in cases where the pool flow increases more rapidly than a linear ramp, the inserted reactivity depends on the instantaneous power distribution and spatial neutronics calculations will be required to provide an accurate determination of the time-dependent coupling between the boron and power distributions, and ensure an accurate scram reactivity calculation. 



\section{References}

1. "PIUS Preliminary Safety Information DocumentPIUS 600," Vols. I-III, ASEA Brown Boveri, December 1989.

2. "Response to Request for Additional Information on PIUS Design," Letter, Kennedy, E.M. (ABB-CE) to Nease, R.L. (USNRC), dated October 16, 1991.
3. "ARMP-02 Documentation," EPRI NP-4574CCM, Part II, Chapter-11, October 1988.

4. "ARMP System Documentation," EPRI Report, RP118-1, Part-II, Chapter-6, September 1977.

5. J. Fisher and R. Grow, "Evaluation of Discrepancies in Assembly Cross Section Generator Codes," Volume 4, EPRI NP-6147, July 1993. 
PIUS Core Performance Analysis

J. F. Carew, A. Aronson, D. M. Cokinos, A. Prince, E.C. Selcow

Brookhaven National Laboratory

Upton, NY 11973

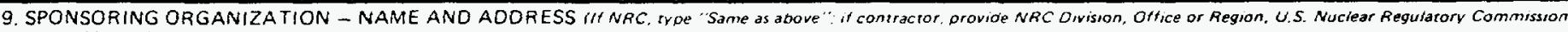
and mailing adoress.)

Division of Reactor Program Management

Office of Nuclear Reactor Regulation

U.S. Nuclear Regulatory Commission

Washington, DC 20855-0001

10. SUPPLEMENTARY NOTES

D.C. Scaletti, NRC Technical Monitor

11. ABSTRACT $(200$ words or jess)

A detailed evaluation of the fuel burnup dependent power distribution and the scram reactivity for the PIUS reactor design has been performed. The analyses were carried out using the CPM lattice physics and NODE-P2. core neutronics/thermal-bydraulics codes and are based on the information provided in the PIUS Preliminary Safety Information Document.

Cycle depletion calculations were performed for a set of nine representative initial core loadings and the threedimensional core power distributions were determined. These calculations indicate that the PIUS radial $\mathrm{F}_{\Delta \mathrm{h}}$ and total $F_{Q}$ power peaking is significantly stronger than indicated by the PIUS reference design values.

The scram reactivity resulting from the injection of highly borated pool water was calculated for a series of timedepandent linear ramp and square-wave pon' flows. The three-dimensional distribution of the pool water throughout the core was modeled and the spatial reactivity effects of the distributed boron were determined. For pool flows that increase as a linear ramp, the spatial reactivity effects of the distributed boron were very small. In this case, a constant core-average boron reactivity coefficient can be used to model the PIUS scram reactivity.

12. KEY WOROSIOESCR!PTORS (List words or phrases that wwil assist researchers in locating phe repart.)

PIUS, core performance, power distribution, PWR reactors, reactor cores, boron, burnup, heat transfer, hydraulics, neutron transport, scram, reactivity coefficients, soluble poisons, three-dimensional calculations

\begin{tabular}{|c|}
\hline $\begin{array}{l}\text { 13. AVAILABILITY STATEMENT } \\
\text { Unlimited }\end{array}$ \\
\hline 14. SECUAITY CLASSIFICATION \\
\hline $\begin{array}{l}\text { This Pagel } \\
\text { Unclassified }\end{array}$ \\
\hline $\begin{array}{l}\text { (This Report) } \\
\text { Unclassified }\end{array}$ \\
\hline 15. NUMBER OF PAGES \\
\hline 16. PRICE \\
\hline
\end{tabular}

